\title{
Public Policy and Venture Capital Backed INNOVATION
}

\author{
CHRISTIAN KEUSCHNIGG
}

\section{CESIFO WORKING PAPER NO. 1066 \\ CATEGORY 1: PUBLIC FINANCE}

OCTOBER 2003

Presented at $3^{\text {rd }}$ German-Norwegian Seminar on Public Economics, June 2003

\footnotetext{
An electronic version of the paper may be downloaded

- from the SSRN website: Www.SSRN.com

- from the CESifo website: www.CESifo.de
} 


\title{
Public Policy and Venture CAPital Backed INNOVATION
}

\begin{abstract}
This paper discusses the role of public policy towards the venture capital industry. The model emphasizes four margins: supply of entrepreneurs due to career choice, entry of venture capital funds and search for investment opportunities, entrepreneurial effort and venture capital advice during the start-up period, and introduction of new goods by successful startups. The paper considers short- and long-run comparative static and welfare effects of policy reform with regard to capital gains taxation, innovation subsidies, public R\&D spending and other policy initiatives.
\end{abstract}

JEL Classification: D82, G24, H21, H25, H32.

Keywords: innovation, venture capital, double moral hazard, public policy.

\author{
Christian Keuschnigg \\ IFF - University of St. Gallen \\ Varnbuelstrasse 19 \\ CH-9000 St. Gallen \\ Switzerland \\ Christian.Keuschnigg@unisg.ch
}

The paper was presented in seminars at the Universities of St.Gallen, Bielefeld, Frankfurt and Mannheim, at the annual meetings 2003 of the Swiss Society for Economics and Statistics in Berne, the 3rd German Norwegian Seminar in Public Economics in Munich, the European Meeting of the Econometric Society in Stockholm, and the $59^{\text {th }}$ Congress of the International Institute of Public Finance in Prague. I appreciate stimulating comments by seminar participants and the discussants Roger Gordon, Andreas Haufler and Thorsten Koeppl. 


\section{Introduction}

Young technology firms are an important source of innovation and growth. For this reason, policy makers have increasingly focussed attention to the conditions for business creation in the technology sectors. It seems that a large number of high quality entrepreneurs with promising ideas emerges more easily in an active research environment. However, potential entrepreneurs must confront some formidable barriers if they intend to commercialize their ideas by starting a firm. Among the most often cited barriers to start new firms are lack of capital and commercial inexperience. Innovative young firms have high potential but are very risky as well. Developing a business idea into a new marketable product involves formidable technological and managerial risks. Given that these firms cannot show yet a past track record and have not yet accumulated sufficient collateral, it is difficult to raise external risk capital. A further difficulty for external financiers is that the main ideas are embodied in the entrepreneur's person. Start-up entrepreneurs have not yet proven their ability to manage a firm. They need not only money to finance start-up investment and research expenditure but also business contacts, strategic advice and other managerial support in building the firm. Experienced venture capitalists (VCs) can offer "informed capital" by giving both money and managerial advice.

A considerable theoretical and empirical literature in financial economics has explored how VCs screen, select, finance, monitor and advise their portfolio companies [see Aghion and Tirole (1994), Bascha and Walz (2001), Bergemann and Hege (1998), Casamatta (2003), Cumming and MacIntosh (2002), Hellmann (1998), Hellmann and Puri (2000,2002), Inderst and Müller (2003), Kaplan and Strömberg (2000,2001), Repullo and Suarez (1999), Schmidt (2003), and the research summarized in Gompers and Lerner (1999)]. This literature is largely partial equilibrium and studies in detail the dynamics of the relationship and optimal contractual arrangements between VCs and entrepreneurs. Gromb and Scharfstein (2002) and Michelacci and Suarez (2002) investigate models of equilibrium entrepreneurship. This paper is on the real side of VC finance and considers the development of new firms beginning with an early seed phase, followed by a VC 
financed start-up period and ending with the introduction of a new good when the firm matures to production stage. An analysis of start-up entrepreneurship and innovation in industry equilibrium is important since the main policy interest in a viable $\mathrm{VC}$ sector focuses on its role as an engine of innovation driven growth and job creation in new industries [European Commission (1994,1998), Botazzi and DaRin (2002)].

Empirical evidence shows that VC can significantly promote innovation and business growth. Based on a sample of firms located in Silicon valley, Hellmann and Puri (2000, 2002) show that VC importantly enhances the professionalization and commercial orientation of young firms. ${ }^{1}$ VC backed firms introduce more radical innovations and pursue more aggressive market strategies compared to other start-ups. For example, once a VC joins the firm and provides finance, the probability of introducing a new product jumps up by a factor of more than three! Rapid market introduction is strategically important since the first firm enjoys a first mover advantage. On a more aggregate level, Kortum and Lerner (2000) show that a Dollar of R\&D spending in VC backed firms creates more patents and more radical innovations than the same expenditure in other firms. They calculate that VC financed R\&D accounts for roughly 14 percent of U.S. industrial innovation in 1998 although it amounts to only about 3 percent of all R\&D funds.

The real effects of venture capital, i.e. the ability to locate and select promising projects and to add value in terms of strategic business advice, depend not only on the VCs' own managerial qualifications and investment knowhow but also on their incentives to be actively engaged in portfolio companies. The supply of experienced financiers with useful business contacts and knowledge of the industry is a scarce resource that is not easily accumulated in short order and may become a considerable bottleneck in the development of a healthy VC sector. An equilibrium analysis of the VC industry should pay due attention to the slow entry of experienced financiers. The other precondition for the development of an active $\mathrm{VC}$ sector and a high rate of business creation is the supply

\footnotetext{
${ }^{1}$ Keuschnigg and Nielsen (2002) model the coexistence of bank and VC financed firms in a common market where the strategic advice of VCs helps firms to earn a quality premium over other firms in the market. See Black and Gilson (1998) for an informal discussion of bank versus VC finance.
} 
of entrepreneurs with innovative ideas. The case study by Becker and Hellmann (2002) identified the lack of skilled entrepreneurs as a prime reason for the slow development of VC in Germany. Representatives of the industry often complain about the lack of high quality entrepreneurs as well. An active research environment is certainly conducive to the creation of innovative firms. The VC industry tends to be geographically concentrated in the neighborhood of universities and other centers of basic research. The human capital created in these institutions expands the supply of inventive people who might consider to turn their research ideas into a business start-up. The government might be able to concentrate research spending in areas with a potential for commercial applications and a correspondingly high probability of spin-offs. It can also spend on other complementary measures such as entrepreneurial training to encourage more spin-offs.

To turn a promising idea into a new firm, researchers must also face the right incentives to give up safe employment for a risky entrepreneurial career. Given their lack of commercial experience, entrepreneurs need strategic business advice in addition to capital. The success of new ventures hinges not only on the entrepreneur's research expertise but also on the willingness of VCs to become closely involved in the firm. Given the unique skills and specialization of each side of the relationship, a suitable matching of entrepreneurs and financiers tends to be subject to frictions. Therefore, the frequency of $\mathrm{VC}$ financed business creation will depend on equilibrium market tightness, i.e. the relative supply of inventive entrepreneurs in need of VC and of experienced VCs in search of investment opportunities. Once an investment is undertaken, a financial contract must be designed to allocate the right incentives for value creating effort. Since both the entrepreneur and the VC must simultaneously contribute to the venture, they need both to participate in the upside potential of the firm. In focusing on the effects of $\mathrm{VC}$ on the quality and quantity of innovative business creation, this paper necessarily adopts a somewhat simpler model of financial contracting that captures nevertheless the essence of the problem. In our simple framework of double moral hazard, a straight equity contract suffices to implement an optimal contractual arrangement. ${ }^{2}$

\footnotetext{
${ }^{2}$ The finance literature has emphasized the importance of staging, syndication, allocation of control
} 
The paper investigates the welfare properties of industry equilibrium and analyzes a range of public policies that are meant to promote innovation by facilitating start-up entrepreneurship in new industries [see Boadway and Tremblay (2002) for an informal policy discussion of welfare issues with respect to innovation]. A specific policy analysis of $\mathrm{VC}$ finance from a public finance perspective is largely missing. The financial economics literature has abstained from an explicit formal analysis of public policy [see Lerner (2002) for a verbal discussion of important policy issues], and the public finance literature has not considered specific models of VC backed entrepreneurship. Gompers and Lerner (1998) and Poterba (1989a,b) have empirically investigated the effects of the capital gains tax on VC financed entrepreneurship and have found that the impact of the tax is mainly on the entrepreneurs' career choice. Gordon (1998), Cullen and Gordon (2002), and Rosen (2002) demonstrate that taxes can impair entrepreneurship. None of these contributions in public finance consider the specific aspects of VC finance.

This paper is close to Keuschnigg (2002) and Keuschnigg and Nielsen (2003a,b) who analyze the effects of taxes on VC backed entrepreneurship. These authors, however, allocate all bargaining power to VCs, do not consider the matching of $\mathrm{VC}$ in a search market and also do not model the effect of VC backed entrepreneurship on innovation. In particular, this paper extends the analysis by explicitely considering the entry decision of VCs and their choice of the number of portfolio companies to finance and advise. This paper distinguishes a short- and long-run equilibrium and explains not only the number of firms but also the number of VC funds in the long-run industry equilibrium. The paper is importantly related to Inderst and Müller (2003) and, in particular, shares their shortand long-run analysis of VC entry in a search market but importantly extends their work rights and use of convertible securities to overcome incentive problems [see Bergloef (1994), Casamatta (2003), Gompers (1995), Hellmann (1998), Neher (1999), Hart (2001), Tirole (2001) and Schmidt (2003), for example]. Taking account of these aspects of VC contracts requires a dynamic and more difficult modeling. Kaplan and Strömberg (2001, p.427) emphasize, however, that cash flow and control rights are more like complements rather than substitutes. Our simpler static model with straight equity finance should thus roughly capture the incentive problems between entrepreneurs and VCs. 
by endogenizing venture returns in an explicitly modeled output market for innovative goods and by an extended analysis of public policy.

The paper now proceeds with section 2 where a model of $\mathrm{VC}$ backed innovation is introduced. Starting from an untaxed market equilibrium, section 3 considers the comparative static and welfare effects of various piecemeal policy reforms, both in the shortand the long-run. These policy initiatives include public spending on basic research, grants for experimental research in the seed phase, entry subsidies to VCs, a tax or alternatively an investment tax credit on start-up investment spending, capital gains taxation and, finally, output subsidies to mature firms that have successfully entered the product market. Section 5 concludes.

\section{The Model}

To take account of the small size of the venture capital (VC) industry, we distinguish a large traditional and a small innovative sector where start-up firms introduce new goods. Production and finance in the traditional sector poses no special problems. In the entrepreneurial sector, however, the market orientation and growth of new firms can benefit substantially from the close cooperation and joint effort of technology entrepreneurs and commercially experienced venture capitalists (VCs).

VC backed business creation involves the following sequence of events ("time line"). First, the government specifies the policy environment. Second, potential entrepreneurs undertake a seed investment and search for VC financing. VCs, in turn, search for profitable investment opportunities. Third, after having found a suitable partner in a matching market, VCs and entrepreneurs bargain over an incentive compatible contract. Fourth, given the terms of the contract, a fixed start-up investment is undertaken and entrepreneurs and VCs expend joint effort to make the firm a success (double moral hazard). Fifth, risk is resolved, i.e. the firm matures to production stage or fails. Finally, profits are shared according to the contract terms. Agents spend on consumption of innovative 
and traditional goods. Given the sequential nature of decisions, the model is solved by backward induction. We thus start with production of established firms and consumer spending, given the income derived in previous stages of the $\mathrm{VC}$ cycle.

\subsection{Demand}

Depending on the previous career, agents are endowed with disposable net income $y^{i}$ which they spend on traditional and innovative goods,

$$
U^{i *}=\max _{D^{i}, Z^{i}}\left\{u\left(D^{i}\right)+Z^{i}-l^{i} \quad \text { s.t. } \quad Z^{i}+V D^{i} \leq y^{i}\right\}
$$

Earning income may require a welfare reducing effort $l^{i}$ by agent $i \in[0,1]$. The homogeneous traditional good $Z^{i}$ is the numeraire. The quantity $D^{i}$ yields convave utility, $u^{\prime}>0>u^{\prime \prime}$, where $D^{i}$ is a subutility over consumption $x_{j}^{i}$ of differentiated goods as in Dixit and Stiglitz (1977). The upper index denotes the identity of the agent and the lower index indicates the specific brand or variety, $j \in[1, N]$, which is available at a price $q_{j}$. The basket of innovative goods is purchased at a price index $V$ given by

$$
V \cdot D^{i}=\min _{x_{j}^{i}}\left\{\int_{0}^{N} q_{j} x_{j}^{i} d j \quad \text { s.t. } \quad\left[\int_{0}^{N}\left(x_{j}^{i}\right)^{1 / \rho} d j\right]^{\rho} \geq D^{i}\right\}, \quad \rho=\frac{\sigma}{\sigma-1}>1 .
$$

Different varieties are imperfectly substitutable where $\sigma=\rho /(\rho-1)>1$ is the constant elasticity of substitution. When $\sigma \rightarrow \infty$, the innovative good is homogeneous with perfectly substitutable varieties. Given a quantity $D^{i}$, standard optimization yields a closed form solution for derived demand and the price index,

$$
x_{j}^{i}=\left(V / q_{j}\right)^{\sigma} \cdot D^{i}, \quad V=\left[\int_{0}^{N} q_{j}^{1 /(1-\rho)} d j\right]^{1-\rho} .
$$

Assuming an isoelastic specification $u(D)=\phi^{1 / \lambda} D^{1-1 / \lambda} /(1-1 / \lambda)$, demand for the final good (or basket of differentiated brands) is ${ }^{3}$

$$
u^{\prime}\left(D^{i}\right)=V, \quad D=\phi V^{-\lambda}, \quad \lambda<\sigma .
$$

\footnotetext{
${ }^{3}$ It will be seen that firm entry expands supply but also stimulates demand. The restriction $\lambda<\sigma$ ensures that firm entry reduces excess demand in the product market.
} 
The assumed structure of preferences in (1) implies several properties of demand. The separability and linearity eliminates income effects in effort choice and demand for innovative goods. All agents demand the same quantity D. Assuming a mass one of households, this is also aggregate demand. Derived demand $x_{j}$ is identical across agents as well. With a large number $N$ of varieties, individuals take the price index and aggregate quantity, $V$ and $D$, as given and independent of any specific variety price $q_{j}$. Therefore, the perceived price elasticity of demand for good $j$ is $\left(d x_{j} / x_{j}\right) /\left(d q_{j} / q_{j}\right)=-\sigma$, see (3).

Since demand for innovative goods as in (2-4) is indepent of income, all changes in income are absorbed by demand for traditional goods, $Z^{i}=y^{i}-V D$. Substituting this into the utility function yields indirect utility equal to the sum of effort adjusted income and consumer surplus over innovative goods,

$$
U^{i *}=y^{i}-l^{i}+C(V), \quad C(V)=u(D)-V D, \quad C^{\prime}(V)=-D .
$$

The derivative of consumer surplus $C^{\prime}$ uses the optimality condition (4).

\subsection{Production and Effort}

Production in the traditional sector is standard and poses no special incentive problems. One unit of labor yields one unit of output. Perfect competition implies a wage equal to the output price which is normalized to unity, $w=1$. With $L$ workers employed in manufacturing, supply of the traditional good is $L$.

In the innovative sector, each entrepreneurial firm is specialized in the production of one brand and supplies the entire market segment. Once a start-up firm has successfully matured to production stage, it produces $x_{j}$ units of brand $j$, using $x_{j}$ units of the traditional good as an input. The technology is linear with an input output coefficient of one. Government possibly offers an output subsidy $z^{X}$. Since firms are monopolists in their market segment and brands are imperfectly substitutable, they can exploit local market power to set a profit maximizing price,

$$
\pi_{j}=\max _{q_{j}}\left\{\left(1+z^{X}\right) q_{j} x_{j}-x_{j} \quad \text { s.t. } \quad\left(d x_{j} / x_{j}\right) /\left(d q_{j} / q_{j}\right)=-\sigma\right\} .
$$


Maximizing profits leads firms to set the price equal to a mark up $\rho$ over unit costs (equal to one). Pricing thus results in a profit margin equal to $\rho-1$,

$$
\left(1+z^{X}\right) q=\rho, \quad \pi=(\rho-1) x=\left(1+z^{X}\right) q x / \sigma .
$$

Sales are read from the demand curve in (3).

The profits of a venture as in (7) will materialize only if the firm successfully matures to production stage. In the start-up phase, the business idea must be developed to a marketable good which is a risky activity subject to a high failure rate. Only a fraction $p$ of all start-ups eventually succeed while the rest fails before any profit is earned. In this case, output is zero by assumption and profits never materialize. It is assumed that the firm's success probability depends on the entrepreneur's more technologically oriented effort $e$ and the VC's managerial involvement and advice $a$. Efforts are assumed intangible, non-verifyable and non-contractible. Both types of inputs are continuous. To keep the analysis tractable, the success probability is specialized to

$$
p=p(e, a)=p_{0} e^{\epsilon} a^{\alpha}, \quad \alpha+\epsilon<1 .
$$

The parameter restriction implies decreasing returns to effort, i.e. the success rate is concave in a proportional increase in joint effort.

Apart from intangible effort, the firm must also invest a fixed quantity $I$ of traditional goods during the start-up phase. The private cost amounts to $\left(1+t^{I}\right) I$ since such investment is possibly subsidized $\left(t^{I}<0\right)$ or taxed $\left(t^{I}>0\right)$ by the state.

\subsection{Making a Deal}

Entrepreneurs are assumed to have no own wealth and must rely on an outside investor to fund the project. Being inexperienced in commercial matters, they seek not only capital but also strategic business advice. After having located a suitable partner, the VC and the entrepreneur must strike a deal. When bargaining over a contract they anticipate how the financial incentives will later on determine the level of effort. Since both partners 
make a valuable contribution, they must both share in the upside potential of the firm to strengthen their incentives for effort at the margin. Incentive compatible profit sharing can be supported by a simple equity contract. The deal is that the $\mathrm{VC}$ pays a price $Q$ for a stake $1-s$ in the firm, leaving a share $s$ to the entrepreneur. Since the entrepreneur has no own wealth, the VC's price $Q=B+\left(1+t^{I}\right) I$ must pay for the entire start-up cost plus some upfront payment $B$. With this arrangement, and given tax rates $t^{E}$ and $t^{F}$ of the entrepreneur and VC (index $F$ for financier), expected income or capital gains after taxes amount to

$$
Y^{E}=\left(1-t^{E}\right)[s p \pi+B], \quad Y^{F}=\left(1-t^{F}\right)\left[(1-s) p \pi-B-\left(1+t^{I}\right) I\right] .
$$

If the firm were sold after the start-up phase, an investor would pay a price $\pi$ equal to the level of profits at production stage. The value of the venture is $\pi$. The VC's expected capital gain on this deal is $(1-s) p \pi-Q$ and is subject to a capital gains tax at rate $t^{F}$ if there is any. The entrepreneur makes an initial capital gain $B$ upon concluding the deal, and $s p \pi$ when the firm is sold at the beginning of the production stage. ${ }^{4}$

The expected income or capital gain must be high enough to compensate for the entrepreneur's effort and opportunity cost which is the outside wage in manufacturing. Both agents incur intangible effort costs which are assumed linear with $\beta$ and $\gamma$ being the relevant marginal costs. The entrepreneur can leave the firm and earn a wage in the traditional sector if no agreement is found. By the participation condition, her expected income net of effort cost must be at least as high as her outside wage, i.e. she must receive a non-negative surplus $S^{E} \geq 0$,

$$
\begin{aligned}
S^{E} & =Y^{E}-\beta e-w, \quad S^{F}=Y^{F}-\gamma a, \\
S & =Y^{E}+Y^{F}-\gamma a-\beta e-w .
\end{aligned}
$$

The VC must not only break even on its investment to pay back the funds raised but must also receive compensation for the managerial effort spent on advising the portfolio

\footnotetext{
${ }^{4}$ The distinction between capital gains and ordinary income is somewhat blurred in our framework. Instead of a capital gains tax, one might alternatively interpret $t^{E}$ as the entrepreneur's personal income tax rate which applies to her dividends $s \pi$ received during production stage and her upfront payment $B$ which could also be a non-performance related base salary.
} 
companies. Her surplus on a single portfolio company ist $S^{F}$. The VC's entry decision occurs at the beginning of the VC cycle. Her opportunity cost in terms of an outside wage is distributed on a portfolio of firms, see section 2.5 below. Adding up yields a joint surplus $S=S^{E}+S^{F}$ per firm.

When bargaining over a deal, the VC and entrepreneur must anticipate how the terms of the contract determine incentives for effort at later stages. This gives rise to the two incentive compatibility constraints $I C^{E}$ and $I C^{F}$ which are stated as first order conditions for effort choice. The Nash bargaining problem is

$$
\begin{aligned}
\max _{s, B, e, a} & \left(S^{E}\right)^{\xi} \cdot\left(S^{F}\right)^{1-\xi} \quad \text { s.t. } \\
I C^{E}: & \left(1-t^{E}\right) s p_{e}(e, a) \pi=\beta \\
I C^{F}: & \left(1-t^{F}\right)(1-s) p_{a}(e, a) \pi=\gamma .
\end{aligned}
$$

Optimal efforts are chosen simultaneously, taking the involvement of the other partner as given. Since the upfront payment $B$ and the outside wage $w$ are already sunk at effort stage, and since the need for fixed capital spending $I$ is unrelated to effort levels, they cannot have an impact on effort choice. Efforts exclusively depend on the incentives created by the agreed profit sharing and are simultaneously determined by the two incentive constraints, giving $e(s, \cdot)$ and $a(s, \cdot)$. Substituting into the definitions of surplus reduces the problem to finding profit maximizing values of the equity stake $s$ and upfront payment $B$. These two components of the financial contract differ in an important way that allows for a recursive solution. The profit share influences incentives in subsequent effort stage and, thus, the size of the pie to be distributed, while the upfront payment $B$ does not since it is not related to performance. In bargaining over the joint surplus, the entrepreneur and $\mathrm{VC}$ will therefore first agree on a Pareto efficient share $s$ to advance their joint interest and then adjust $B$ to find an appropriate distribution of the surplus. This results in a contract on the "Pareto frontier" as in Inderst and Mueller (2003).

Proposition 1 (Profit Sharing and Joint Effort) (a) Entrepreneurial effort e and managerial support a increase with venture returns $\pi$ and decline with taxes $t^{E}$ and $t^{F}$. A 
higher share $s$ boosts the entrepreneur's effort but undermines $V C$ advice.

(b) The Pareto-optimal share $s$ increases with a higher tax $t^{F}$ on expected VC income and falls with a higher tax on entrepreneurial income $t^{E}$. The profit share is independent of venture returns as well as taxes when rates are identical, $t^{E}=t^{F}$.

Proof. See appendix A and, in particular, equations (A.2) and (A.6) for part (a) and (A.6-8) for part (b).

Taxes discourage effort because they cut the returns to effort. More interestingly, effort depends not only on one's own tax rate but also on the tax rate applied to the other partner. When the VC gets taxed more heavily, she advises less intensively. Since efforts are complements, less VC support also reduces the returns to entrepreneurial effort. For this reason, a tax on VCs reduces the entrepreneur's effort. The same cross effect applies to the taxation of entrepreneurs, see (A.2). Furthermore, allocating a larger stake to the entrepreneur at the expense of the VC's share strengthens the returns to entrepreneurial effort while weakening the VC's incentives, with obvious consequences for effort choice.

Part (b) is also intuitive. Raising the entrepreneur's tax discourages her effort and makes her contribution to the joint surplus more expensive. Hence, the team relies more on VC effort by raising the VC's share and leaving a correspondingly smaller share to the entrepreneur. When the $\mathrm{VC}$ is taxed more, the team finds it optimal to raise the entrepreneur's share. If the same tax rate applies to both, the Pareto-optimal share is a constant as in (A.8), and exclusively depends on the relative effectiveness of the VC's and entrepreneur's effort in raising the survival rate. In the symmetric case of $\alpha=\epsilon$, the share is exactly half, $s=1 / 2$. Note finally, that in all cases the agreed equity stake is independent of the upfront payment.

Proposition 2 (Sharing Joint Surplus) Bargaining over the upfront payment B, the entrepreneur gets a share $\tilde{\xi}$ and the VC a share $1-\tilde{\xi}$ of the joint surplus,

$$
S^{E}=\tilde{\xi} \cdot S, \quad S^{F}=(1-\tilde{\xi}) \cdot S, \quad \tilde{\xi} \equiv \frac{\left(1-t^{E}\right) \xi}{\left(1-t^{E}\right) \xi+\left(1-t^{F}\right)(1-\xi)}
$$


Proof. Since $B$ has no influence on $s, a$ and $e$, maximizing (11) with respect to $B$ yields a necessary condition $\left(1-t^{E}\right) \xi S^{F}=\left(1-t^{F}\right)(1-\xi) S^{E}$. Expanding appropriately and noting $S=S^{E}+S^{F}$ gives (12).

The upfront payment $B$ is chosen to allocate to each partner a share of the joint private surplus as in (12). VCs and entrepreneurs divide according to their modified bargaining

power $\tilde{\xi}$. The entrepreneur's share becomes independent of tax rates, $\xi=\tilde{\xi}$, only if both agents are subject to the same capital gains tax rate.

\subsection{Matching of Venture Capital}

Research and managerial skills are fundamentally different. It is thus assumed that an exogenously given part $M$ of the population of mass one is endowed with managerial skills and the rest $1-M$ with variable research abilities that might lead with some effort to new product designs. The $M$ born managers either choose a management career in manufacturing or set up a VC fund to coach new firms. With $F$ denoting the number of financiers, or VCs, the managerial skills are endogenously split according to $M=$ $F+(M-F)$. In fact, we will take this decomposition as fixed in the short-run while it is endogenously determined in a long-run equilibrium with free entry. This reflects the observation by Gompers and Lerner (1999, p.4): "Not only is it difficult to raise a new venture capital fund without a track record, but the skills needed for successful venture capital investing are difficult and time-consuming to acquire".

The rest of the population $1-M$ is endowed with research skills enabling them to become workers or researchers, giving a split $1-M=R+(1-M-R)$ as in Figure 1 below. Among all researchers with a business idea only a part $E$ succeeds to obtain finance and advice and are able to start a firm. This mass of start-up entrepreneurs results from a matching allocation between researchers seeking finance and VCs seeking investments. After having sunk an effort cost in the initial attempt at entrepreneurship, the rest $R-E$ turns to employment in the traditional sector, giving a decomposition $R=E+(R-E)$. Total employment $L$ in the traditional sector thus consists of $1-M-R$ 'born workers' who 
avoided entrepreneurship right from the beginning, plus $R-E$ unmatched researchers, plus $M-F$ born managers who chose not to enter the VC business:

$$
L=(1-M-R)+(R-E)+(M-F)=1-E-F .
$$

In other words, who is not a start-up entrepreneur or a $\mathrm{VC}$ ends up being a worker in the traditional sector. For simplicity, all types of agents earn the same wage in the old economy, irrespective of whether they are endowed with managerial or technological skills.

In the VC market, $F$ VCs search for profitable investment opportunities and $R$ researchers, or potential technology entrepreneurs, consider to start a firm and seek informed capital. VCs are specialized in rather different industries and have accumulated specific contacts with clients, suppliers, and specialized personnel that are valuable only in the same industry. The same holds for the specific knowledge of the market opportunities of certain technologies. The VCs' commercial and managerial knowhow is therefore not equally useful for all entrepreneurial ventures. A productive matching of VCs and entrepreneurs is subject to frictions. It takes time to locate a suitable partner especially since a pair of $\mathrm{VC}$ and entrepreneur enter a close relationship in the start-up firm. In a static model, this time consuming search activity is reflected in the fact that only part of the potential entrepreneurs participating in the search market locate a financier, and only part of the financing offers are successfully invested. ${ }^{5}$

Formally, we assume that each of the $R$ researchers who consider entrepreneurship prepares a business plan and searches for informed capital. ${ }^{6}$ On the other side of the VC market, each VC chases for profitable deals by making $v F$ financing offers in total. Only a smaller number $E$ of them is successfully matched and results in a deal. A linear homogeneous technology $E=E(v F, R)$ determines the matching rates $^{7}$

$$
E / v F=f(\theta), \quad E / R=f(\theta) / \theta, \quad \theta \equiv R / v F .
$$

\footnotetext{
${ }^{5}$ In reality, the funds raised are usually considerably higher than the funds invested. The excess funds presumably wait for other promising investments.

${ }^{6}$ Before a VC joins the firm, these seed investments are often financed by family or other sources. The model treats this as intangible research and search effort rather than real expenditure.

${ }^{7}$ Diamond (1990) has introduced a search model of the credit market. Michelacci and Suarez (2002)
} 
Using $f(\theta) \equiv E(1, \theta)$, the matching rates satisfy $f^{\prime}(\theta)>0$ and $d[f(\theta) / \theta] / d \theta<0$ as well as $0<f(\theta)<1$ and $0<f(\theta) / \theta<1$. Out of all $v F$ financing offers, only a fraction $f(\theta)$ is actually financed. Therefore, a VC finances and advises an average number of portfolio firms equal to $E / F=f(\theta) v$. The ratio $\theta$ of potential entrepreneurs $R$ to the number of financing offers $v F$ is a measure of market tightness. In taking market tightness as given, a $\mathrm{VC}$ can generate a larger number of deals and end up with a larger portfolio of firms if she raises her search intensity $v$.

On the other market side, only a fraction $f(\theta) / \theta$ of potential entrepreneurs locate a VC. Matching splits potential entrepreneurs into $E=[f(\theta) / \theta] R=f(\theta) v F$ active VC financed entrepreneurs while the others, $R-E$, turn to their outside opportunity and remain workers. The higher is $\theta$, the tighter is the VC market, and the less likely will potential entrepreneurs locate VC finance to start a firm, $d[f(\theta) / \theta] / d \theta<0$. In contrast, VCs will identify profitable investments more easily, $f^{\prime}(\theta)>0$, so that a larger fraction of their offers translates into a successful deal. The change in market tightness reflects the increase in $R$ and $v F$ on each side of the market. The sensitivity of successful matches, i.e. the number of VC backed start-ups, with respect to aggregate search activity of VCs and potential entrepreneurs is measured by the matching elasticities

$$
\eta=\frac{R}{E} \frac{d E}{d R}=\frac{\theta f^{\prime}}{f}, \quad 1-\eta=\frac{v F}{E} \frac{d E}{d v F}=\frac{f-\theta f^{\prime}}{f} .
$$

\subsection{Searching for a Deal}

To allow for a finitely elastic supply of potential entrepreneurs, we assume that agents differ by their inventive ability, i.e. the required research effort for a new business idea. ${ }^{8}$ When an agent decides to enter the search competition for VC, she incurs a cost $k^{i}$ and and Inderst and Müller (2003) similarly apply a matching function to study the allocation of informed capital to start-up firms. They do not endogenize the VC's search intensity.

${ }^{8} \mathrm{~A}$ key assumption is that this heterogeneity in research cost does not carry over to the quality of the business idea. Once the firm is started, they are all homogeneous. This helps to concentrate on the moral hazard problems during the start-up phase. 
becomes a potential technology entrepreneur. This cost is interpreted as an effort cost or time input that is necessary to produce an idea for a new product or service and prepare a business plan. We assume, for simplicity, that the population with research skills is distributed uniformly in $k^{i}$, i.e. all types are represented with uniform density. Without loss of generality, research effort costs are specialized to

$$
k^{i}=k(i, G)=\frac{k_{0}}{G} \cdot i^{\kappa}, \quad k_{i}>0>k_{G}, \quad \kappa \equiv i k_{i} / k^{i}, \quad i \in[0,1-M] .
$$

Private research effort in the seed phase can be reduced by public spending on research and development $(\mathrm{R} \& \mathrm{D})$ in areas that are particularly amenable to commercial applications. Basic research and the associated human capital formation reduces the research cost of potential entrepreneurs and thereby raises the likelihood of a spinoff.

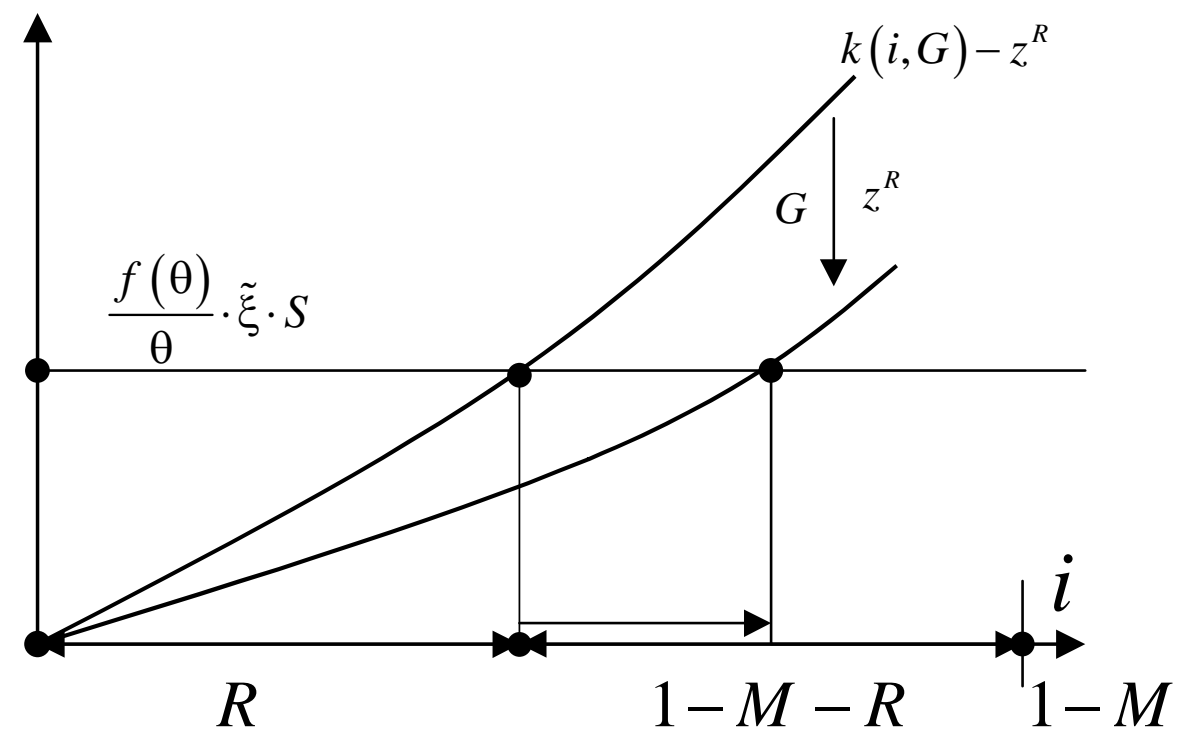

Figure 1: Seed Investments

Preparing for an entrepreneurial career requires to invest in research effort and prepare a business plan that can be presented to a VC for financing the venture. The government may wish to offer a research grant or entry subsidy $z^{R}$ to encourage potential entrepreneurs in the seed phase to experiment with new ideas. An agent considers entrepreneurship and participates in the search market for $\mathrm{VC}$ only if the expected return pays at least for this (re-)search effort, net of the entry subsidy. The expected return is the share of the joint surplus of the start-up firm that she expects to bargain with the VC as in Proposition 2. 
The number of entrepreneurs in search of $\mathrm{VC}$ is now defined by the critical agent $R$ who just breaks even on her research effort cost net of the entry subsidy,

$$
\frac{f(\theta)}{\theta} \cdot \tilde{\xi} S=k(R, G)-z^{R}
$$

Figure 1 illustrates how the indifference condition for the marginal researcher splits the population between workers and potential entrepreneurs who do research on a business idea and, based on this seed investment, prepare a business plan to be presented to VCs. The figure also shows how increased public R\&D funding as well as research grants for seed investments can raise the supply of entrepreneurs.

It is assumed that VCs give up a managerial job in the old economy when choosing to set up a VC fund. The government may wish to encourage this decision with an entry subsidy $z^{F}$. A VC fund is viable only if expected surplus (profits less advisory effort cost) on the entire portfolio of firms suffices to compensate for the foregone wage income $w$ of its manager and a progressively increasing search effort cost $\delta(v)$. When convenient, we may specify $\delta(v)=\delta_{0} \cdot v^{1+\omega} /(1+\omega)$ with $\omega, \delta_{0}>0$ :

$$
\Omega=\max _{v^{i}}\left\{v^{i} f(\theta) \cdot S^{F}-\delta\left(v^{i}\right)-w+z^{F}\right\}, \quad \delta^{\prime}(v)>0, \quad \delta^{\prime \prime}(v)>0 .
$$

In chasing for investment opportunities, a VC endogenously chooses search intensity $v$ which corresponds to the number of financing offers posted. The VC's search activity results in a deal only with some probability. The matching probabilities derives from aggregate $\mathrm{VC}$ search effort equal to $v F=\int_{0}^{F} v^{i} d i$ under symmetry. In making $v^{i}$ offers, an individual VC takes market tightness $\theta$ as given and expects to realize $f(\theta) v^{i}$ deals where each one yields a surplus $S^{F}$ as in (12). A VC's optimal search intensity equates marginal expected benefit and cost from an extra offer,

$$
f(\theta) \cdot(1-\tilde{\xi}) S=\delta^{\prime}\left(v^{i}\right)
$$

This condition determines individual portfolio size $f(\theta) v$ which depends on individual search intensity, the VC's surplus, and aggregate market tightness. 


\subsection{Equilibrium}

Only a fraction of $R$ potential entrepreneurs with a business plan succeed to locate a VC, leading to $E$ start-up firms as in (14). Depending on the effort of both the entrepreneur and VC, a new firm succeeds to develop and introduce the product on the market with probability $p(e, a)$. In the aggregate, a fraction $p$ of all start-ups matures to production stage, leaving $N$ firms to supply differentiated goods,

$$
N=p(e, a) \cdot E, \quad E=f(\theta) v \cdot F
$$

In restricting attention to symmetric equilibria, the price and quantity indices in (2-3) are

$$
V=N^{1-\rho} q, \quad D=N^{\rho} x, \quad V D=N q x .
$$

Since the component price is a fixed mark-up over the exogenously given unit cost as in (7), it cannot adjust to clear the product market. Instead, market clearing depends on sales $x$ and thereby profits $\pi$ per firm. Since profits are the ultimate reward of business formation, they determine the supply of new goods as in (20). On the demand side, when market size is finite, higher sales per brand must reduce demand for the number of differentiated products. The price index $V$ increases with the price of components $q$ but declines with product variety $N$. The latter effect reflects the gains from increasing specialization. More variety stimulates demand. Substituting demand for the composite good in (4) into (3) and replacing the price index by its symmetric form in (21) yields the consumers' trade-off between scale and variety. This trade-off yields the demand for variety as a function of quantity per brand,

$$
N=\left[\frac{\phi}{x q^{\lambda}}\right]^{\mu}, \quad \lambda<\sigma \Rightarrow \mu=\frac{1}{\rho-(\rho-1) \lambda}>0 .
$$

The demand for variety falls when each single brand is consumed in larger quantity.

Several features of the model simplify the equilibrium solution. First, mark-up pricing in (7) fixes the component price $q$ solely in terms of the output subsidy. Second, profit is proportional to sales, $\pi=(\rho-1) x$, so that the scale of production $x$ also stands 
for profits or venture returns. Third, proposition 1 states that the entrepreneur's profit share is independent of venture returns and other endogenous variables, see also (A.5). The profit share is affected only by differential tax rates but otherwise remains a fixed constant. Therefore, joint effort and the success probability depend on profits, and thus $x$, as in (A.2), $p(x)$. Fourth, the bargaining solution of Proposition 2 together with (9-10) implicitely determines an upfront payment which, in turn, fixes the joint surplus as a function profits and thereby sales $x, S(x){ }^{9}$

With this information, we can now solve for equilibrium in the markets for $\mathrm{VC}$ and for new goods. We first turn to the short-run equilibrium with a fixed number $F$ of VCs. For a given value of expected joint surplus $S(x)$, equilibrium in the market for $\mathrm{VC}$ is brought about by an adjustment of market tightness as illustrated in Figure 2 of section 3.1 below. The demand for VC reflects the agents' willingness to engage in seed investments. The potential entrepreneur's entry decision in (16), repeated as SR in (23), defines a demand schedule for $\mathrm{VC}$ in terms of financing offers $v^{D}$ which is downward sloping in market tightness $\theta$. In a tighter market, researchers are less likely to obtain a $\mathrm{VC}$ offer, i.e. the expected return line in Figure 1 shifts down. Fewer agents thus decide to engage in seed investments and search for VC. The upward sloping supply schedule $v^{S}$ for VC offers results from search investments of VCs as in (18), repeated as SF in (23). For any given project surplus $S$, VCs are more likely to locate a profitable deal when the market is very tight. Expected returns to search are up, leading to increased search intensity and a larger number of financing offers $v^{S}$. As is illustrated in Figure 3 below, market tightness adjusts until the market for VC clears.

Higher sales $x$ and profits earned in the product market boost the joint surplus per project and thereby strengthen the entry incentives of both researchers and VCs, shifting

\footnotetext{
${ }^{9}$ If taxes are uniform, $t^{E}=t^{F}=t,(9)$ yields $Y^{E}+Y^{F}=(1-t)\left[p \pi-\left(1+t^{I}\right) I\right]$, so that joint surplus in (10) depends on $x$ exlusively. Bargaining in (12) then determines $S^{E}$ and thereby $Y^{E}$ and $B$, all depending on $x$. The paper emphasizes very much this symmetric case. If taxes are differential, then (9-10) yield $S(x, B)$. The bargaining result in (12) reads $S^{E}(x, B)=\tilde{\xi} \cdot S(x, B)$ which determines $B(x)$ and ultimately $S(x, B(x))$, or $S(x)$ for short.
} 
up both the demand and supply schedule in Figure 2. As a result, equilibrium search activity $v$ expands but the adjustment of market tightness is ambiguous and most likely rather small. As a result, $\mathrm{VC}$ portfolio size $f(\theta) v$ increases ${ }^{10}$ allowing for more $\mathrm{VC}$ backed start-ups. Higher venture returns also strengthen incentives for joint effort and thereby make firms more likely to succeed. For both reasons, the supply of new goods, as stated in (20), increases with venture returns $x$ while variety demand falls by the arguments given in (22). The condition for product market equilibrium PM is repeated in (23) and illustrated in Figure 3:

$$
\begin{aligned}
P M: & {\left[\phi /\left(x q^{\lambda}\right)\right]^{\mu} } & =p(x) \cdot f(\theta) v \cdot F \\
S R: & k(R, G)-z^{R} & =S(x) \cdot \tilde{\xi} \cdot f(\theta) / \theta, \quad R=\theta v F \\
S F: & \delta^{\prime}(v) & =S(x) \cdot(1-\tilde{\xi}) \cdot f(\theta), \\
F E: & \Omega & =S(x) \cdot(1-\tilde{\xi}) \cdot f(\theta) v-\delta(v)-w+z^{F} .
\end{aligned}
$$

The supply of experienced VCs cannot expand in short order. In the short-run equilibrium with a fixed number of VC funds $F$, the product market condition PM and the investment conditions SR and SF relating to VC demand and supply determine three unknowns $x, \theta$ and $v$. With fixed $F, \mathrm{VC}$ funds derive rents on their scarce managerial resource. Such rents should attract more VCs after a sufficiently long period of skill formation. Rents tend to dissipate when the industry is crowded with more VCs. In the competitive long-run equilibrium with free entry (FE), a zero profit condition $\Omega=0$ endogenizes $F$, the equilibrium number of VCs. ${ }^{11}$

\subsection{Welfare}

To arrive at a welfare based evaluation of various policy initiatives, one must first identify potential market distortions and the associated margins for welfare improvements. Indirect utility in (5) depends on income, adjusted for effort costs, plus consumer surplus

\footnotetext{
${ }^{10}$ This statement is shown more precisely in the appendix, see the next section.

${ }^{11}$ Technically, SF and FE combine to $v \delta^{\prime}(v)=\delta(v)+z^{F}-w$ and fix the search intensity $v$. Given $v$, SR and SF solve for $\theta(F)$ and $x(F)$ so that PM yields the equilibrium number $F$ of VCs.
} 
derived from the consumption of innovative goods. Appendix B derives an aggregate welfare measure, and appendix C.1 shows how welfare changes along with equilibrium policy effects, see (C.7). To avoid complicated tax base effects, the paper considers only small policy changes relative to an initial equilibrium without taxes and subsidies. Using the hat notation to denote percentage changes relative to this untaxed position (such as $\hat{x} \equiv d x / x)$, welfare changes according to ${ }^{12}$

$$
\begin{aligned}
d U^{*} & =(q-1) x N \cdot \hat{x}+(q-1) x N \cdot \rho \hat{p} \\
& +(1-s) \pi N \cdot \epsilon \hat{e}+(1-(1-s)) \pi N \cdot \alpha \hat{a} \\
& +(\eta-\xi) S E \cdot \hat{\theta}+\left(K_{G}-1\right) G \cdot \hat{G} .
\end{aligned}
$$

The first term relates to mark-up pricing in (7). In exploiting market power, mature firms charge a price $q>1$ in excess of marginal cost and thereby restrict demand. An increase in sales and thereby consumption of differentiated goods raises welfare (scale effect). With a fixed profit margin, increased sales lead to higher profits which, in turn, encourages joint effort and boosts the success rate. Accordingly, a larger number of startups succeeds to production stage and thereby expands product variety. The second term relates to this variety effect which is also proportional to the margin $q-1$.

The third and fourth terms indicate that both an increase in entrepreneurial effort and VC advice augment welfare. These two terms point to an underinvestment in effort. If both agents were able to committ to mutually agreed effort levels in their joint interest, they would maximize joint surplus in (9-10), $S=p(e, a) \pi-\beta e-\gamma a-I-w$, without being further restricted by any incentive constraints. They would decide on first best levels of effort given by $\pi p_{e}(e, a)=\beta$ and $\pi p_{a}(e, a)=\gamma$. Accordingly, each individual should be full residual claimant on her investment of extra effort so that marginal costs $\beta$ and $\gamma$ are equated with the full social returns $\pi p_{a}$ and $\pi p_{e}$. However, since effort is not verifyable and

\footnotetext{
${ }^{12}$ We slightly rewrite (C.7) by using $E=R f(\theta) / \theta$ as in (14) and $S=S^{*}$, as it holds in the untaxed initial equilibrium, see the remark on (B.4). The result in (24) follows upon noting the change in market tightness, $\hat{\theta}=\hat{R}-\hat{v}-\hat{F}$. Further, $K_{G} \equiv-\int_{0}^{R} k_{G}(i, G) d i$ stands for the aggregate private savings on account of larger public R\&D spending.
} 
not contractible, a double moral hazard problem emerges. Neither of the two agents will be able to credibly committ to any promised effort level so that effort must be elicited by means of financial incentives. Both agents must simultaneously participate in the upside potential of the firm and must therefore share profits. The incentive constraints in (11) thus result in an underinvestment of entrepreneurial effort and managerial support. While agents must bear the full private cost of effort, the entrepreneur is able to appropriate only a share $s$ of the marginal increase in expected profits while a part $1-s$ actually benefits the VC. A similar argument applies to the VC's advisory effort. For this reason, any policy that succeeds to strengthen joint effort, yields first order welfare gains. As the second line in (24) shows, these welfare gains are proportional to the external gains or spillovers of individual effort to the other side of the relationship. ${ }^{13}$

The first term in the last line of (24) points out the welfare consequences of a change in $\mathrm{VC}$ market tightness $\theta$. This term would be absent if the so-called Hosios condition $\xi=\eta$ were satisfied (Hosios 1990). Search intensity and entry are efficient if the property rights on the returns to search are appropriately allocated (via bargaining power $\xi$ ) to correspond to each party's effectiveness in generating a match, as measured by the matching elasticity $\eta$. Suppose now that entrepreneurs' bargaining power falls short of their matching elasticity, $\xi<\eta$. In this case, entrepreneurs are able to negotiate only a relatively small share of the joint surplus, leaving a too large share to VCs. Correspondingly, entrepreneurs are too reluctant to pursue seed investments and to enter the search market while VCs' incentives to search for new investment opportunities are excessive. Market

\footnotetext{
${ }^{13}$ In principle, the government can compensate for the beneficial spillovers of individual effort on the other side of the team by setting negative tax rates satisfying $\left(1-t^{* E}\right) s=1$ and $\left(1-t^{* F}\right)(1-s)=1$. Substituting into (11) shows that this would induce first best effort. Before drawing any immediate policy conclusions, however, one should emphasize that the industry has partly developed its own solutions to alleviate the problem. Schmidt (2003) among others has shown that the use of convertible securities can go a long way to allocate the right incentives at the right time to each partner. Stage financing, i.e. the tying of further financing rounds to the achievement of predefined milestones, also addresses the problem. However, as long as both inputs must be supplied simultaneously at least in some stages of the firm's development, the problem never fully disappears
} 
tightness $\theta$ is inefficiently low. Correspondingly, a policy would boost welfare by raising market tightness via stimulating seed investments or retarding VCs' search activities.

Finally, the last term in (24) points to a productive role of the public sector. The government could allocate a part $G$ of public $\mathrm{R} \& \mathrm{D}$ spending to activities that are more amenable for commercial applications. More spending would raise welfare as long as the marginal reduction of the entrepreneurs' entry costs in the aggregate exceeds the marginal budget cost, $K_{G}=\int_{0}^{R}-k_{G}(i, G) d i>1$.

\section{Piecemeal Policy Reform}

Public policy towards the VC industry includes a number of actual and potential strategies. To begin with, policy makers and representatives of the industry often consider the capital gains tax as the most important tax barrier to VC investments. Second, many countries subsidize start-up capital cost by means of interest subsidies and direct investment tax credits to young firms which corresponds to choosing $t^{I}<0$ in the present model framework. Third, entrepreneurial experimentation can be encouraged by research grants for seed investments, $z^{R}$ in our model. Other initiatives might aim to attract additional VCs, for example by awarding an entry subsidy $z^{F}$. Fourth, public innovation policy often aims to facilitate technology transfer to the private sector by shifting a larger part $G$ of R\&D funds to applied areas with promising commercial applications. Such spending raises the probability of spin-offs and is conducive to innovative business start-ups. Fifth, innovation is rewarded by local market power and monopolistic profits for the specialized brands that successful start-ups introduce in the market. On the negative side, mark-up pricing restricts demand and consumer surplus which can be addressed in terms of an output subsidy $z^{X}$. The following analysis explores the comparative static and welfare effects of such policy initiatives. The results are conveniently summarized in Tables 1 and 2. Except for subsection 4.4 below, we will assume that any net budget cost is financed with a lump-sum tax that involves no excess burden. 
Table 1: Comparative Statics

\begin{tabular}{ccccccccccc}
\hline & & $N$ & $x$ & $p$ & $S$ & $v$ & $\theta^{*}$ & $v f(\theta)$ & $\Omega$ & $F$ \\
\hline$z^{X}$ & $\mathrm{SR}$ & ++ & ++ & ++ & ++ & + & + & + & + & 0 \\
& $\mathrm{LR}$ & + & + & + & + & 0 & - & - & 0 & + \\
$z^{F}$ & $\mathrm{SR}$ & 0 & 0 & 0 & 0 & 0 & 0 & 0 & + & 0 \\
& $\mathrm{LR}$ & + & - & - & - & - & - & - & 0 & + \\
$z^{R}, G$ & $\mathrm{SR}$ & + & - & - & - & + & ++ & ++ & + & 0 \\
& $\mathrm{LR}$ & ++ & - & - & - & 0 & + & + & 0 & + \\
$t, t^{I}$ & $\mathrm{SR}$ & + & - & + & + & + & + & + & + & 0 \\
& $\mathrm{LR}$ & ++ & - & ++ & ++ & 0 & - & - & 0 & + \\
\hline
\end{tabular}

Note: $N$ number of mature firms, $x$ sales and venture returns, $p$ success rate, $S$ joint surplus, $v$ VC search intensity, $\theta$ VC market tightness, $v f(\theta)$ VC portfolio size, $\Omega$ VC rent, $F$ number of VC funds. $\left.{ }^{*}\right)$ Sign holds for $\eta>\xi$. $z^{X}$ Output subsidy, $z^{F}$ VC entry subsidy, $z^{R}, G$ research grant and public R\&D spending. $t, t^{I}$ Selffinanced capital gains tax cut.

Table 2: Long-run Welfare

\begin{tabular}{|c|c|c|c|c|}
\hline Welfare effects & $z^{X}$ & $z^{F}$ & $z^{R}, G$ & $t, t^{I}$ \\
\hline Scale & + & - & - & - \\
\hline Variety & + & - & - & + \\
\hline Joint effort & + & - & - & + \\
\hline Market tightness* & + & - & + & - \\
\hline$R \& D$ cost & 0 & 0 & + & 0 \\
\hline \multicolumn{5}{|c|}{$\begin{array}{l}\text { Note: Lines refer to welfare effects in (24). } \\
{ }^{*} \text { Sign holds for } \eta>\xi \cdot z^{X} \text { Output subsidy, } \\
z^{F} \text { VC entry subsidy, } z^{R}, G \text { research grant } \\
\text { and public R\&D spending. } t, t^{I} \text { Self-financed } \\
\text { capital gains tax cut. }\end{array}$} \\
\hline
\end{tabular}

We consider both a short-run effect where the number of VCs with specialized investment knowhow is fixed, and a long-run response with free entry and zero profits. Below, we log-linearize the equilibrium conditions in (23) and investigate how the initial equilibrium is displaced after a small policy change. The hat notation considers logarithmic 
changes relative to the initial position, such as $\hat{x} \equiv d \ln (x)=d x / x$. To avoid division by zero, one defines $\hat{z}=d z /(1+z)$ for subsidies and $\hat{t}=d t /(1-t)$ for tax rates. To further simplify the analysis, we assume $z^{R}=z^{F}=0$ in the initial state. Detailed calculations are found in appendix $\mathrm{C}$.

\subsection{Output Subsidy on Innovative Goods}

The invention and introduction of new goods allows new firms to enjoy local market power on account of product differentiation. In our model of horizontal product innovation, mark-up pricing over marginal cost unduly restricts demand and reduces consumer surplus. Further, if a specialized producer introduces a new good, the gains from variety reduce the price index, thereby stimulate demand and boost sales and profits of other producers as well. Mark-up pricing and demand externalities can be addressed by an output subsidy. Starting from a laissez-faire equilibrium with other taxes set to zero, this section considers the effects of a small output subsidy given to VC backed firms.

The immediate effect of the subsidy is to reduce the demand price $q$ of innovative goods while the producer price is still chosen as a fixed mark-up over unit cost. Profits of a specialized firm are not immediately affected but increase only if the subsidy stimulates demand and sales in equilibrium. By (7),

$$
\hat{q}=-\hat{z}^{X}, \quad \hat{\pi}=\hat{x}
$$

Short-Run Adjustment: We first consider the case of a fixed number of VCs. The reduction in demand prices creates excess demand in the product market and, thus, stimulates sales and profits of mature firms. The profit per firm is a measure of venture returns which affects incentives in earlier stages of the VC cycle. Entrepreneurs supply more effort during the start-up phase when the reward is higher. VCs advise more intensively as well, see the incentive constraints in (11). Since efforts are complements, they are mutually reinforcing, leading to an overall increase in the firms' success probability as in 
(C.1). One stage earlier, the entrepreneur must bargain with a VC to finance the start-up investment cost of the venture. The VC buys an equity stake for a price that pays for the start-up cost and in addition includes a non-performance related upfront payment. The contract results in the entrepreneur and VC sharing the joint surplus of the project as in Proposition 2. An increase in venture returns $\hat{\pi}=\hat{x}$ obviously boosts the joint surplus, see (C.3). ${ }^{14}$

In the seed phase, researchers anticipate their share in the joint surplus which determines their incentives to conduct experimental research leading to a business plan. The marginal investment condition is stated in (17) and illustrated in Figure 1. The expected return on seed investment prior to VC finance is $\frac{f(\theta)}{\theta} \cdot \xi S$ and consists of the probability to obtain VC times the entrepreneur's share in the expected joint surplus. The expected return just matches the research cost $k(R, G)$ of the marginal entrepreneur $R$. The higher is market tightness $\theta$, the lower is the probability of obtaining finance which shifts down the horizontal line in Figure 1. Consequently, fewer researchers will attempt entrepreneurship so that fewer financing offers $v^{D}$ are needed to satisfy their demand for VC finance. The investment condition thus defines a demand curve for VC in terms of market tightness $\theta$ which is downward sloping as in Figure $2 .{ }^{15}$

The supply curve follows from the search investment of VCs who expend effort to locate profitable investments. The expected return on search is the probability $f(\theta)$ of locating a suitable project times the VC's share in joint surplus, and must match with marginal cost of search effort. The marginal cost increases with search intensity or the number of financing offers, and the matching probability increases with market tightness. For any given $S$, the investment condition (19) thus defines an upward sloping supply

\footnotetext{
${ }^{14}$ Since this scenario considers only an isolated increase of the output subsidy, all other policy instruments are set to zero, i.e. $\hat{t}=\hat{t}^{I}=0$.

${ }^{15}$ Formally, replacing $R$ by $\theta v F$, and taking the expexted surplus $S$ as given, condition (17) can be solved for demand $v^{D}$ in terms of $\theta$. Solving equation SR in (C.4) for $\hat{v}$ gives the log-linearized demand curve while SF is the supply curve for VC. Note that demand and supply is defined per VC whereas the aggregate quantity is $v F$.
} 
curve $v^{S}$ for $\mathrm{VC}$ as illustrated in Figure 2. In reducing demand prices, the output subsidy creates excess demand for innovative goods and thereby boosts the joint surplus $S$ of a start-up firm that is shared among entrepreneur and VC. The subsidy thus shifts up both the supply and demand curves for VC and thus expands VC finance as captured by search intensity $v$. If entry of entrepreneurs is more elastic relative to the search activity of VCs, $\omega>\kappa$, market tightness will increase as well, see (C.8) for the formal analysis. This condition is a reference case which would always hold if the supply of entrepreneurs were perfectly elastic $(\kappa=0)$.

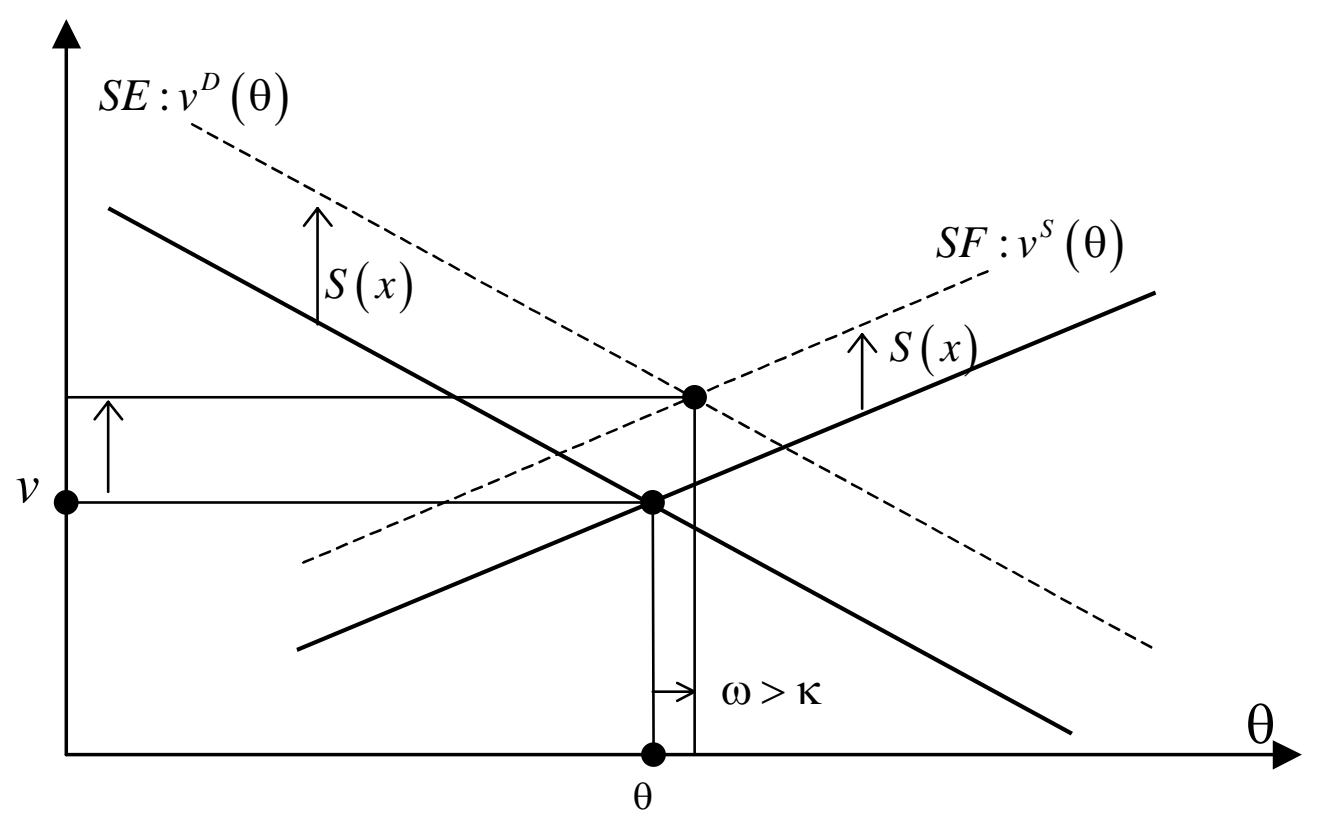

Figure 2: Supply and Demand for VC

Consider now product market equilibrium in terms of supply and demand for new goods. To obtain the supply curve in terms of venture returns $x$, note that $\hat{S}$ and $\hat{x}$ are positively linked in (C.3). In raising joint surplus, higher venture returns contribute to increased market tightness and boost search intensity in Figure 2. Each VC thus posts not only a larger number of financing offers but also succeeds to strike a deal on a larger share of these offers when market tightness is higher. Further, since higher venture returns strengthen joint effort, a larger fraction of these deals eventually result in market introduction of new goods. Putting these effects together shows how an increase in venture returns raises the number of mature firms $N$ so that a larger range of differentiated 
products are on offer. This upward sloping supply curve is illustrated in Figure 3 and is formally derived in condition PM in (C.4) or (C.9) in its final form.

For any given component price $q$, the demand side (3-4) defines a trade-off between scale and variety in consumption. In other words, more quantity $x$ per brand reduces the demand for variety $N$. This trade-off defines a downward sloping demand curve for new goods in terms of sales $x$ where the component price $q$ is a shift parameter. Figure 3 illustrates what is shown formally in PM of (C.4), i.e. $\hat{N}=-\mu \hat{x}+\mu \lambda \hat{z}^{X}$. The intersection of supply and demand curves yields the market clearing level of venture returns $x$. Raising the output subsidy cuts the consumer price of all brands and stimulates demand. Holding sales $x$ and thereby the scale of consumption constant, the demand curve for new goods shifts to the right in Figure 3. The subsidy leads to a new product market equilibrium with increased sales per product and a larger number of specialized firms. Formally, (C.10-11) state the relative changes compared to the initial equilibrium, $\hat{x}=\zeta_{x} \hat{z}^{X}>0$ and $\hat{N}=\left(\Delta_{X}-\mu\right) \frac{\mu \lambda}{\Delta_{X}} \hat{z}^{X}>0$.

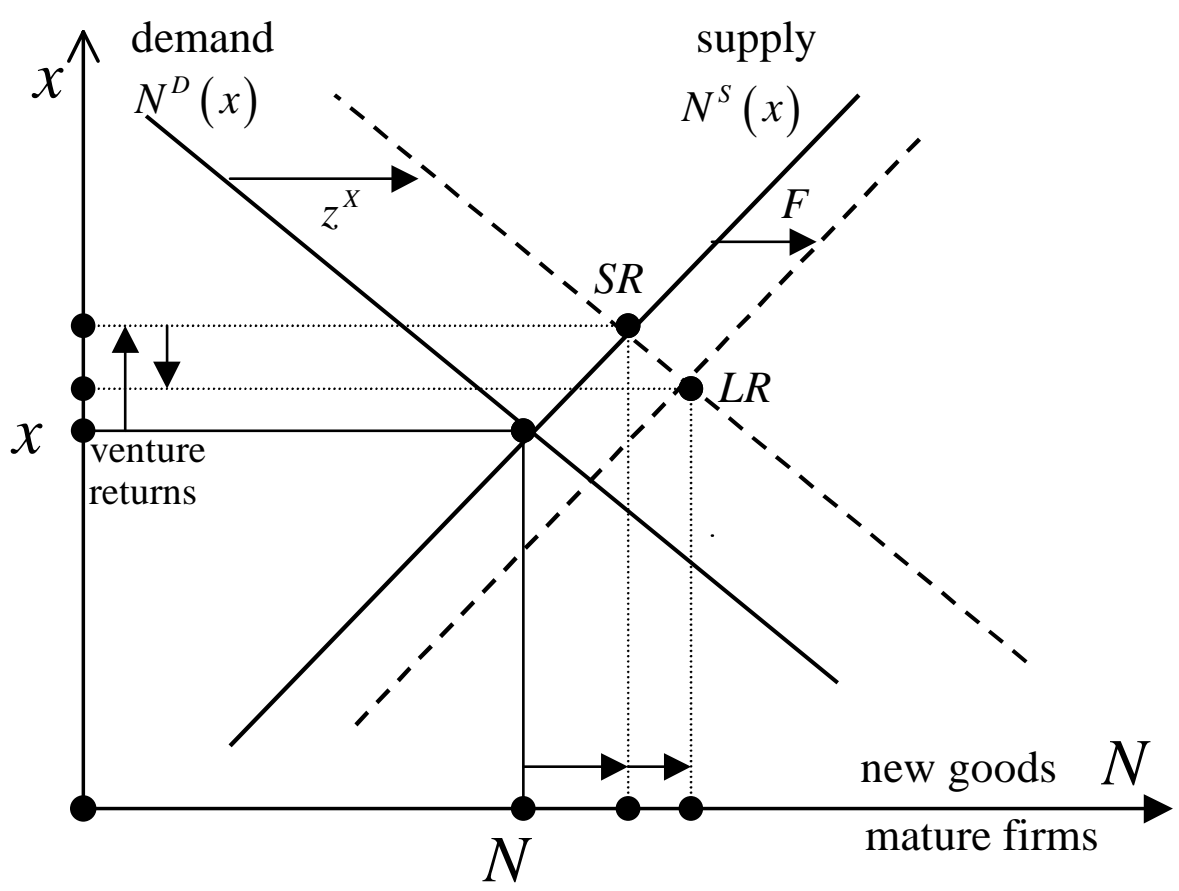

Figure 3: Product Market Equilibrium

Knowing the equilibrium adjustment of venture returns, one can calculate all other 
repercussions of the output subsidy. Of particular interest are the welfare consequences which are formally stated in (24). Keeping other policy instruments at zero, the output subsidy yields welfare gains on several margins. The first two terms in (24) relate to the output market distortion with respect to scale and variety resulting from monopolistic competition. ${ }^{16}$ The subsidy squeezes demand prices and thereby offsets markup pricing of innovative firms. Since demand is repressed on account of prices in excess of marginal costs, this demand stimulation yields welfare gains proportional to the price wedge, $(q-1) x N \hat{x}$. Second, the increase in sales of individual firms boosts profits, $\hat{\pi}=\hat{x}$. Improved venture returns sharpen incentives for joint efforts, raises the success probability of start-ups and thereby the number of mature firms. The introduction of a larger range of innovative goods raises consumer surplus due to gains from variety, $(q-1) x N \cdot \rho \hat{p}$. The second line in (24) reflects the beneficial effects of the output subsidy on joint effort. In the untaxed equilibrium, the wedge between the social and private returns to effort is $1-s$ for the entrepreneur and $1-(1-s)$ for the VC, leading to inefficiently low effort levels. In raising venture returns, the output subsidy boosts both entrepreneurial effort and managerial support, thereby raises expected joint surplus, and leads to a first order welfare gain as indicated in the second line of $(24)$.

Finally, the subsidy boosts the expected surplus of new start-up firms that is shared among entrepreneurs and VCs as a result of bargaining. It thereby raises the prospects of initial research efforts of potential entrepreneurs and increases the number of business plans proposed while VCs search more intensively for investment opportunities. If entry of potential entrepreneurs is more elastic than the supply of informed capital, $\omega>\kappa$, the policy raises VC market tightness in Figure 2. The effectiveness of entrepreneurial seed investments in generating matches and raising the number of VC backed start-ups is measured by the elasticity $\eta$. If the entrepreneurs' bargaining power determining their share in the joint surplus falls short of their matching effectiveness, then entrepreneurial entry is too hesitant relative to the willingness of VCs to finance new ventures. Conse-

\footnotetext{
${ }^{16}$ Note that the same wedge $q-1$ measures two distortions with respect to scale and variety. In standard models of monopolistic competition, the scale effect is often absent, leaving only the variety effect.
} 
quently, an increase in market tightness boosts welfare in case of $\eta>\xi$. If the property rights on initial seed investments and VC search effort are efficiently distributed and exactly correspond to the effectiveness of entrepreneurs and VCs in launching start-up firms $(\eta=\xi)$, the search market for $\mathrm{VC}$ is efficient so that a small change in market tightness is devoid of welfare consequences. Obviously, $\eta<\xi$ implies that a tighter market for VC is detrimental to welfare. If entrepreneurial entry is more elastic than VC search activity, $\omega<\kappa$, the subsidy reduces market tightness which turns around the welfare results. The preceeding discussion is summarized in

Proposition 3 (Output Subsidy in the Short-Run) (a) Starting from an untaxed position, the output subsidy increases venture returns $x$ which boosts entrepreneurial effort $e$ and managerial VC support $a$ and results in a higher success rate $p$ of start-up firms.

(b) It boosts joint surplus $S$ and raises market tightness $\theta$ (if $\omega>\kappa$ ), VC search intensity $v$ and rents $\Omega$, VC portfolio size $v f(\theta)$, and the number $N$ of mature firms.

(c) Starting from laissez-faire, it yields welfare gains by raising consumer surplus due to (i) higher demand for each variety and (ii) more product variety, (iii) by encouraging joint effort and (iv), if $\eta>\xi$, by encouraging entrepreneurial entry relatively more than $V C$ search activity (higher market tightness). If $\eta \gtrless \xi$, the welfare gain from higher market tightness is zero or negative. The welfare results in (c.iv) are reversed if entrepreneurial entry is relatively less elastic, $\omega<\kappa$, and market tightness declines.

Proof. (a) See (C.10) for $x$ and (C.1) for $e, a$, and $p$. (b) (C.13) reports $\hat{S}>0$, implying $\hat{\theta}, \hat{v}$ and $\hat{v}+\eta \hat{\theta}$ for portfolio size in (C.8). Rents increase in line with search intensity as in (C.16), and (C.10) gives $\hat{N}$. (c) See the discussion of (24).

Free Entry of VCs: The number of VCs is fixed in the short-run since it takes time to acquire the necessary market knowledge, financial expertise and reputation of a successful VC. However, when an output subsidy or any other structural change boosts profits, these rents should eventually attract more VCs to the industry. When more projects get funded 
by a larger number of VCs, the supply curve for new products shifts to the right in Figure 3 which reduces equilibrium venture returns by $\hat{x}=-\zeta_{F} \hat{F}$ as noted in (C.10). When the joint surplus of VC backed firms erodes and more VCs must share the market, $\hat{S}<0<\hat{F}$, each one will search less intensively and finance a smaller portfolio as in (C.8), and end up with smaller rent as in (C.16). The process continues until rents are exhausted and entry comes to a halt. Following an increase in the short-run, VC search intensity is reduced as a consequence of continued entry until it is back to the original value in the long-run, $\hat{v}=0$ in (C.16). To accommodate the extra demand created by the output subsidy, the number of VCs increases to an extent given in (C.19), $\hat{F}=\left(\mu \lambda / \nabla_{F}\right) \hat{z}^{X}>0$.

Since entry $\hat{F}>0$ erodes venture returns, it works to dampen the short-run increase in (C.10), $\hat{x}=\zeta_{x} \hat{z}^{X}-\zeta_{F} \hat{F}$, and by implication joint efforts, the success rate and project surplus. The number of mature firms, in contrast, increases beyond the short-run effect simply because there are more VCs to finance projects. The final, long-run effects of the output subsidy are computed in (C.20). Interestingly, the long-run change in market tightness is in the opposite direction of the short-run effect. This reversal is intuitive, however. Since entrepreneurial talent is distributed unevenly, the supply of entrepreneurs remains finitely elastic even in the long-run while free entry makes the supply of VCs perfectly elastic. Obviously, market tightness should fall in the long-run as is verified by (C.20). The same basic formula (24) applies to judge the long-run welfare consequences.

Proposition 4 (Output Subsidy in the Long-Run) (a) Free entry of VCs, $\hat{F}>0$, dampens the short-run increase in sales $x$, surplus $S$, efforts e and $a$, and success rate $p$. (b) The long-run effect on VC search is zero while the subsidy reduces market tightness $\theta$ and portfolio size $v f(\theta)$. The number $N$ of mature firms expands beyond the short-run.

(c) A small output subsidy raises consumer surplus by raising (i) scale, (ii) variety, and (iii) joint efforts. The gains are positive but smaller than in the short-run. Since market tightness declines in the long-run, the short-run welfare effects from entry and search (iv) are reversed and negative if $\eta>\xi$, but positive (zero) if $\eta<(=) \xi$.

Proof. (a) $\hat{e}, \hat{a}$ and $\hat{p}$ are proportional to $\hat{x}$ but the short-run increase in venture 
returns is dampened by $\hat{F}>0$, see $\hat{x}=\zeta_{x} \hat{z}^{X}-\zeta_{F} \hat{F}$ in (C.10). (b) Read (C.20). Given constant $v$, portfolio size $v f(\theta)$ declines in line with $\theta$. The effect on $\hat{N}$ follows from (C.10) combined with the result that the increase in $\hat{x}$ is larger in the short-run than in the long-run. (c) Since $\hat{\pi}=\hat{x}>0$, welfare increases by the first four terms in (24), verifying (i-iii). Part (iv) relates to the last term which changes sign along with $\theta$.

\subsection{Entry Subsidy to Venture Capitalists}

How does the structure of the VC sector change if policy succeeds to attract more managers to finance and advise entrepreneurial firms? One possibility is to encourage the creation of new VC funds by means of an entry subsidy $z^{F}$. The analysis starts from a laissez-faire position with zero VC profits and supposes lump-sum finance of the subsidy. Since the entry subsidy is sunk once a fund is established, it cannot affect later stages of the VC cycle. Consequently, there are no immediate effects on the short-run equilibrium since it does not enter the short-run conditions PM, SR and SF in (23) or in the log-linearized version (C.4). The subsidy simply raises VC profits as in (C.16).

If the policy persists, it will eventually attract new managers to the industry to take advantage of these rents. With given market tightness and the same aggregate demand for $\mathrm{VC}$, each individual VC fund receives less demand when more of them compete for investments. Therefore, the demand curve for the financial offers per VC shifts down in Figure 2, see the effect of $\hat{F}>0$ on $\mathrm{SR}$ in (C.4), while the supply curve reflecting the investment condition SF of an individual VC is not affected. Drawing the demand shift shows that equilibrium market tightness relaxes. Despite of the fact that search intensity and portfolio size also decline as in (C.8), the larger number of funds succeeds to finance more start-up firms. ${ }^{17}$ A fraction $p$ of them succeeds to introduce their product to the market. With a larger number of mature firms, $\hat{N}>0$, the product supply curve shifts to the right in Figure 3. The excess supply of new goods erodes equilibrium venture

\footnotetext{
${ }^{17}$ The number of VC backed start-up firms is $E=v f(\theta) F$ and changes by $\hat{E}=\hat{v}+\eta \hat{\theta}+\hat{F}$. Using (C.8), we obtain $\hat{E}=\frac{(1-\eta)(1+\kappa) \omega}{\Delta_{S}} \hat{F}>0$.
} 
returns by $\hat{x}=-\zeta_{F} \hat{F}$ as computed in (C.10). The joint surplus thus falls and thereby discourages efforts and the success rate. The lower surplus partly destroys the returns to search investments and impairs somewhat the incentives of entrepreneurs to pursue seed investments and of VCs to search for investment opportunities. The net effect of VC entry is stated in

Proposition 5 (VC entry subsidy) (a) VC entry $\hat{F}>0$ reduces venture returns, effort and advice, the success rate and joint surplus of VC backed firms, as well as search intensity of VCs. Market tightness and portfolio size decline.

(b) Welfare declines on account of negative effects on variety, scale, joint effort, and (in case of $\eta>\xi$ ) market tightness.

Proof. (a) $\hat{x}<0$ by (C.10), $\hat{S}<0$ by (C.13), and $\hat{v}<0$ by (C.8). A sufficient condition for $\hat{\theta}<0$ and $\hat{v}+\eta \hat{\theta}<0$, i.e. for market tightness and portfolio size to decline, is $\omega>\kappa$, see (C.8). Entry stops when search intensity is reduced to the extent given in (C.16) which implies a larger number of VC funds as in (C.19). Some long-run effects are given in (C.16). (b) The welfare effects are read form (24).

\subsection{Basic Research and Research Grants}

According to Becker and Hellmann (2002), the supply of high quality entrepreneurs with new innovative ideas is a precondition for the development of a healthy VC sector. Universities and other research centers create technological spillovers which can be exploited by the formation of new firms. ${ }^{18}$ The government could shift a part $G$ of public spending to promote research areas of high commercial value. The human capital created at universities helps people to invent new applications and thereby raises the probability of

\footnotetext{
${ }^{18}$ Zucker, Darby and Brewer (1998) show empirically that the human capital created by frontier research around great universities was a principal determinant of the growth and location of the US biotechnology industry. The conclude "This industry is a testament to the value of basic scientific research." See Audretsch et al. (2003) for a review of the literature and results for Germany.
} 
spinoffs. Start-up entrepreneurship can also be encouraged by complementary activities such as entrepreneurial training. Somewhat simplistically, we assume that these expenditures reduce the private cost of experimental research in the seed phase and thereby encourages more researchers to attempt entrepreneurship with some initial seed investments. Given the need for external financing as well as strategic business advice, the demand for $\mathrm{VC}$ rises. As an alternative, the government might also consider encouraging experimentation with new business ideas by simply handing out small research grants $z^{R}$. Such grants might be given subject to the requirement to produce a business plan, irrespective of whether the entrepreneur succeeds to attract VC finance or not.

In our model, both initiatives reduce private research cost. In shifting down the cost schedule in Figure 1, they raise the mass of agents who try entrepreneurship. The demand for VC grows. In Figure 2, the demand schedule shifts up (not drawn). Since this policy does not directly affect the investment criterion of financiers, the supply curve for VC remains invariant. Market tigthness increases when more entrepreneurs ask for finance. Accordingly, the VC's probability to locate profitable investments rises which strengthens her incentives for search, leading to an increase in the supply of VC in terms of financing offers. With each VC tending a larger portfolio $v f(\theta)$ of firms, more seed investments get started as a VC backed firm, $E=v f(\theta) F$, of which a fraction $p$ matures to production stage, $N=p E$. Consequently, market supply in Figure 3 shifts to the right. Equilibrium venture returns decline as in (C.10) when more firms crowd the market.

The research subsidy does not directly affect the joint surplus of a start-up firm. However, since increased start-up activity spoils sales and profits of individual firms, it thereby retards entrepreneurial effort and managerial support and erodes the joint surplus in the start-up phase. This negative feedback from the market weakens the incentives for search effort that were initially created by the research policy and dampens other reactions as well. However, if the elasticity for variety demand $\mu$ is sufficiently large, the erosion of venture returns will not overturn the incentives for start-up activity created by the research policy. With a large elasticity $\mu$, the product demand curve in Figure 3 is flat so 
that even a small reduction in sales $x$ per brand creates a large demand for new products. Consequently, a minor reduction of sales and profits suffices to create new markets for the extra start-ups resulting from a more active research policy. With this profit destruction effect being small, it cannot overturn the incentives of VCs to search more intensively for new investments when the research policy raises market tightness by stimulating seed investments. Although lower venture returns erode the incentives for effort and thereby reduce the success rate and joint surplus from start-up firms, this negative effect remains small as well when the product demand curve is flat.

In stimulating more seed investments by potential entrepreneurs, the policy contributes to increased market tightness and thereby raises the VCs' probability to attract investments. Larger company portfolios create VC rents which attract new managers to the industry. As more start-ups get financed, more firms will eventually mature to production stage and crowd the market with new products. The reduction in venture returns is thus magnified in the long-run by the entry of VCs, see (A.22). Consequently, joint efforts, the success rate and joint surplus all shrink beyond the short-run effect which impairs search incentives. Entry continues until the short-run increase in VC search intensity is fully reversed and VC rents are exhausted. When there is free entry of VCs in the long-run, the number of VC backed firms in the market is larger but VCs are less engaged to support the portfolio companies with active managerial advice. In this sense, there is more quantity but less quality of VC.

Proposition 6 (Research Policy) (a) In the short-run, research policy boosts the supply of new products $N$ but erodes venture returns $x$. Joint efforts, the success rate and surplus, e, $a, p$ and $S$, fall. Market tightness $\theta, V C$ search intensity $v$, portfolio size $v f(\theta)$ and $V C$ rents $\Omega$ increase if the demand elasticity $\mu$ for variety is sufficiently large.

(b) In the long-run, $V C$ search intensity is back to its initial value $(\hat{v}=0)$ but portfolio size increases with market tightness $\theta$. VC entry is positive, $\hat{F}>0$, venture returns $x$ and thereby $e, a, p$ and $S$ fall while the number of mature firms $N$ increases.

(c) Basic R\&D spending $G$ and small research grants $z^{R}$ both diminish consumer sur- 
plus by reducing (i) scale, (ii) variety, and (iii) joint efforts. (iv) The increased market tightness yields a positive welfare effect if $\eta>\xi$, and a negative (zero) one if $\eta<(=) \xi$. (v) Public R\&D funds $G$ directly boost welfare as long as the aggregate savings of private research cost exceeds the opportunity costs of these funds, $K_{G}>1$.

Proof. (a) In the short-run, $\hat{x}<0<\hat{N}$ by (C.10). By (C.1), $\hat{e}, \hat{a}$ and $\hat{p}$ fall in line with $\hat{x}$ while $\hat{S}<0$ is calculated in (C.13). By (C.14), search intensity increases despite of the negative influence of $\hat{S}<0$ if $\mu$ is sufficiently large. Since a large $\mu$ dampens the effect of a smaller surplus, market tightness and portfolio size similarly increase on account of (C.8). VC rents increase with search intensity by (C.16). (b) Long-run effects follow from (C.16) and (C.22). (c) Noting $\hat{x}<0<\hat{\theta}$, the welfare effects follow from (24).

\subsection{Tax Policy}

Industry representatives cite the capital gains tax as the most important tax barrier against VC investments. Policy makers have often called for tax breaks or even an entire elimination of the capital gains tax to expand the VC industry and thereby stimulate growth and innovation. In general, all business taxes on the profits of start-up firms and VC funds are relevant. To mimick the consequences of a tax break but nevertheless avoid tedious tax base effects, we start from an untaxed equilibrium and introduce a small negative tax (i.e. a subsidy), $\hat{t}<0$. To avoid any cost to the tax payer, this tax break is financed by a start-up tax $\hat{t}^{I}>0$. Since entrepreneurs are wealth constrained, the startup tax is in fact shouldered by financiers who must pay a larger price for their share in the firm, see (9). Note that this tax policy initiative avoids handing out any net subsidy to VC backed start-up firms. Will it nevertheless expand the industry? What are the implications for the quantity and quality of VC finance, and for welfare?

To keep the proposal revenue neutral, the two instruments must be adjusted simultaneously to satisfy the government budget constraint. With a uniform tax, (B.2) implies $t \cdot\left[p \pi-\left(1+t^{I}\right) I\right]=-t^{I} I$. Starting from an untaxed position, reducing the capital gains 
tax requires an increase in the start-up tax equal to

$$
I \cdot \hat{t}^{I}=-(p \pi-I) \cdot \hat{t}
$$

The tax cut directly boosts joint effort and the success rate in (C.1). The start-up tax, in contrast, has no direct impact on effort since it is not related to performance. Both instruments, however, affect the joint surplus of a start-up. Imposing the fiscal budget constraint (26) together with $t=t^{I}=0$ an $I^{N}=I$ in (C.3) yields, with $\zeta_{S X}>1$,

$$
\hat{t}<0 \Rightarrow \hat{S}=-\left(\zeta_{S X}-1\right) \frac{p \pi}{S} \cdot \hat{t}>0
$$

Even though the policy involves no net subsidy to the project, the joint surplus increases because it stimulates effort and thereby offsets the underinvestment problem. Since this higher surplus is shared among VCs and entrepreneurs, it raises the returns to search. Accordingly, VCs look more intensively for investments and more researchers decide for an attempt at entrepreneurship. The demand and supply curves for VC in Figure 2 shift up, implying a higher search intensity and market tightness (when entrepreneurial entry is more elastic than VC search, $\omega>\kappa)$. When VCs expand their company portfolios and finance a larger number of start-ups, as $\hat{S}>0$ implies in (C.8), and when the success rate among these start-up firms is higher on account of increased effort, more firms mature to production stage and succeed to introduce new goods. The product supply curve in Figure 3 shifts to the right, yielding $\hat{x}<0<\hat{N}$. The policy initiative thus erodes equilibrium venture returns. The formal solution in (C.10) takes account of the fact that an erosion of venture returns negatively feeds back on the incentives to expend effort in earlier stages of the VC cycle. Substituting (26) into (C.10) yields the equilibrium impact of the self-financed tax cut:

$$
\begin{aligned}
\hat{x} & =\left[\zeta_{P X}+\left(\zeta_{S X}-1\right) \frac{1+\kappa+(\omega-\kappa) \eta}{\Delta_{S}} \frac{p \pi}{S}\right] \frac{1}{\Delta_{X}} \hat{t}<0, \quad \hat{N}=-\mu \hat{x}>0, \\
\hat{x}-\hat{t} & =-\left[\mu+\frac{1+\kappa+(\omega-\kappa) \eta}{\Delta_{S}} \frac{p \pi}{S}\right] \frac{1}{\Delta_{X}} \hat{t}>0 .
\end{aligned}
$$

When firms in their mature stage are less effective in generating sales and profits, $\hat{x}<0$, entrepreneurs and financiers must expect a smaller joint surplus in the start-up 
phase. After taking account of this negative feedback, the net effect is calculated from (C.13). Imposing the policy restriction (26) yields

$$
\hat{S}=-\frac{\left(\zeta_{S X}-1\right) \mu-\zeta_{P X}}{\Delta_{X}} \frac{p \pi}{S} \cdot \hat{t}>0
$$

The negative feedback effect from lower venture returns is small when the demand schedule in Figure 3 is flat, i.e. when the demand elasticity $\mu$ is large. Equilibrium venture returns then decline by a relatively minor amount so that the direct effect of the tax cut on joint surplus remains dominant. ${ }^{19}$ VCs share in this larger surplus and will search more intensively to expand their company portfolios. VC rents accordingly increase in the short-run which eventually attracts more managers to set up new VC funds. This relaxes the scarce managerial resource in the long-run. We find the following results:

Proposition 7 (Self-financed Tax Cut) (a) In the short-run, the self-financed tax cut given in (26) boosts the supply of new products $N$ but erodes venture returns $x$. Efforts and the success rate, $e, a$, and $p$, all increase. Joint surplus increases if $\mu$ is large. Market tightness $\theta$ (if $\omega>\kappa$ and $\mu$ large), VC search intensity $v$, portfolio size $v f(\theta)$ and $V C$ rents $\Omega$ increase in proportion to the joint surplus.

(b) In the long-run, VC search intensity is back to its initial value ( $\hat{v}=0) . V C$ entry is positive, $\hat{F}>0$. The tax cut raises joint surplus but shrinks portfolio size together with market tightness $\theta$. Venture returns $x$ decline but the tax cut boosts efforts and the success rate, $e, a, p$. The number of mature firms $N$ increases.

(c) The tax cut (i) diminishes welfare on account of a negative scale effect but (ii) raises welfare due to a positive variety effect and (iii) by stimulating joint efforts. These effects are qualitatively the same in the short- and long-run. (iv) The short-run increase in market tightness (if $\omega>\kappa$ and $\mu$ large) yields a welfare gain if $\eta>\xi$, and a loss if $\eta<\xi$. In the long-run, market tightness relaxes if $\mu$ is relatively large, yielding a welfare loss if $\eta>\xi$, and a gain if $\eta<\xi$.

\footnotetext{
${ }^{19}$ Rewrite $\hat{S}=-\frac{\left(\zeta_{S X}-1\right)-\zeta_{P X} / \mu}{\Delta_{X} / \mu} \frac{p \pi}{S} \hat{t}$. Since $\Delta_{X} / \mu \rightarrow 1$ for $\mu \rightarrow \infty$ by (C.11), the effect of the policy reduces to $\hat{S}=-\left(\zeta_{S X}-1\right) \frac{p \pi}{S} \hat{t}$ for very large $\mu$ which is the direct effect noted in (27).
} 
Proof. (a) In the short-run, $\hat{x}<0<\hat{N}$ and $\hat{x}-\hat{t}>0$ by (28). This raises efforts and the success rate as in (C.1) while $\hat{S}>0$ is calculated in (29) for $\mu$ sufficiently large. The changes in $\theta, v, v f(\theta)$ and $\Omega$ follow from (C.8) and (C.16). (b) Free entry in the long-run results in $\hat{v}=0$ and $\hat{F}>0$ by (C.16) and (C.23) where the latter effect hinges on the demand elasticity being large. Although venture returns decline, see (C.24), the tax cut raises joint surplus relative to the initial equilibrium, consistent with positive entry, $\hat{F}>0 \Rightarrow \hat{S}>0$ and $\hat{\theta}<0$, see (C.17). The tax cut enhances efforts and boosts the success rate as in (C.1) sind $\hat{x}-\hat{t}>0$ by (28). Given smaller sales per firm, $\hat{x}<0$, market demand supports a larger number of mature firms, see PM in (C.4). (c) The welfare effects follow from (24) after substituting $\hat{x}<0, \hat{x}-\hat{t}>0$ and $\hat{\theta}$.

The self-financed tax cut fails to achieve unambiguous welfare gains, even if one excludes search distortions $(\eta=\xi)$. Since it expands the supply of mature firms, it reduces sales per firm and thereby produces a negative scale effect. Smaller demand per variety is detrimental since demand is already repressed due to mark-up pricing. The scale effect subtracts from the otherwise positive welfare effects of the tax cut that result from stimulating private effort and joint surplus per project, and from the extra product variety offered by new firms. An output subsidy, in contrast, subsidizes consumer prices and thereby creates extra demand. Consequently, sales per firm and product variety can expand at the same time, allowing for gains from variety and scale. Higher sales mean higher venture returns which strengthen the incentives for private effort. Except possibly for the search distortions, an output subsidy yields welfare gains on all fronts. A targeted output subsidy for innovative firms is thus superior to a tax cut, see Table 2.

\section{Conclusions}

This paper proposed a rich model of the venture capital industry. It emphasizes the need for an active research environment as an important precondition for the supply of high quality entrepreneurs and the contribution of new firms to innovation. The supply of 
entrepreneurs depends on the willingness of inventive persons to give up alternative career opportunities. Start-up entrepreneurs are often commercially inexperienced and thus need informed capital that not only provides finance but also managerial support. This model of venture capital backed start-up firms is embedded in a model of industry equilibrium where a downward sloping demand curve for innovative goods determines the overall size of the product market. The inelastic entry and search activities of entrepreneurs and venture capitalists lead to an endogenously determined market tightness in venture capital finance. The first activity of entrepreneurs is a seed investment in experimental research leading to a business plan that can be presented to a venture capitalist who could provide the required funds and help with strategic business advice. The paper is unique in discussing not only inelastic supply of entrepreneurs but also inelastic supply of venture capital which consists of an optimally determined portfolio size of a fixed number of venture capitalists in the short-run and an endogenously explained number of venture capital funds in the long-run.

Based on this structural model of the venture capital industry, we have considered a rich menu of policy instruments that are able to influence the evolution of the industry. Interestingly, some of the popular policy measures often proposed by governments receive no support in this model. For example, research grants to encourage fresh entrepreneurs, or capital subsidies to reduce the cost of start-up investment, succeed to expand the VC sector. However, they do not help with mark-up pricing and they discourage private effort rather than promote it as is required in a situation of double moral hazard. Similarly, spending on basic research alone is not successful in addressing output market distortions or the problem of double moral hazard, although it will yield welfare gains if the cost reductions to private research in the seed phase exceed the opportunity costs of these funds. Cutting capital gains taxes combined with a tax (rather than a subsidy) on startup capital spending is a useful policy to sharpen incentives for entrepreneurial effort and VC support. This initiative can be made self-financing and does not yield any net subsidy to $\mathrm{VC}$ backed firms. It is thus designed not to obtain more, but more successful start-up firms. The reduced failure rate among start-ups leads to more mature firms introducing 
new goods. An output subsidy to mature firms is seen to be even more favorable, however, and yields multiple dividends. It not only shifts the scale and variety of new firms in the right direction but also sharpens incentives for joint effort.

\section{Appendix}

\section{A Profit Sharing and Joint Effort}

(a) Effort Stage: Appendix A proves proposition 1. Linearizing the incentive constraints (11) allows to uncover the comparative static effects on efforts. The hat notation denotes relative changes such as $\hat{a}=d a / a$. Tax rates, however, can be zero in the initial state. In this case, we define changes relative to the net tax price, $\hat{t}^{E}=d t^{E} /\left(1-t^{E}\right)$, or $\hat{z}^{X}=d z^{X} /\left(1+z^{X}\right)$ etc. The linearized reaction functions are ${ }^{20}$

$$
\begin{array}{ll}
I C^{E}: & (1-\epsilon) \hat{e}=\alpha \hat{a}+\hat{s}+\hat{\pi}-\hat{t}^{E}, \\
I C^{F}: & (1-\alpha) \hat{a}=\epsilon \hat{e}-\frac{s}{1-s} \hat{s}+\hat{\pi}-\hat{t}^{F} .
\end{array}
$$

Solving (A.1) and noting (A.6) below yields the comparative static effects as in part (a),

$$
\begin{aligned}
& \hat{a}=\frac{1}{1-\epsilon-\alpha}\left[\hat{\pi}-\frac{s-\epsilon}{1-s} \hat{s}-\epsilon \hat{t}^{E}-(1-\epsilon) \hat{t}^{F}\right], \\
& \hat{e}=\frac{1}{1-\epsilon-\alpha}\left[\hat{\pi}+\frac{1-s-\alpha}{1-s} \hat{s}-(1-\alpha) \hat{t}^{E}-\alpha \hat{t}^{F}\right], \\
& \hat{p}=\frac{1}{1-\epsilon-\alpha}\left[(\epsilon+\alpha) \hat{\pi}+\frac{(1-s) \epsilon-s \alpha}{1-s} \hat{s}-\epsilon \hat{t}^{E}-\alpha \hat{t}^{F}\right] .
\end{aligned}
$$

(b) Contract Stage: Anticipating effort choice, bargaining finds the optimal contract $s$ and $B$. Agents first agree on a share $s$ to maximize joint surplus and then bargain over $B$ to distribute it. The Pareto efficient share follows from

$$
S=\max _{s}\left\{Y^{E}+Y^{F}-\gamma a-\beta e-w \text { s.t. } \quad(9),(A .2)\right\} .
$$

Using the IC's in (11), the optimality condition is

$$
\frac{d S}{d s}=\left[\left(t^{F}-t^{E}\right)+\left(1-t^{F}\right)(1-s) \cdot \frac{p_{e}}{p} \frac{d e}{d s}+\left(1-t^{E}\right) s \cdot \frac{p_{a}}{p} \frac{d a}{d s}\right] p \pi=0 .
$$

\footnotetext{
${ }^{20} \operatorname{By}(8)$, we have $\hat{p}=\varepsilon \hat{e}+\alpha \hat{a}, \hat{p}_{e}=-(1-\varepsilon) \hat{e}+\alpha \hat{a}$, and $\hat{p}_{a}=\varepsilon \hat{e}-(1-\alpha) \hat{a}$.
} 
Expand the square bracket, $[\cdot]=\left(t^{F}-t^{E}\right)+\left(1-t^{F}\right) \frac{1-s}{s} \frac{e p_{e}}{p} \cdot \hat{e} / \hat{s}+\left(1-t^{E}\right) \frac{a p_{a}}{p} \cdot \hat{a} / \hat{s}$. Using $e p_{e}=\epsilon p$ and $a p_{a}=\alpha p$ from (8), noting the elasticities in (A.2), and canceling all proportional terms, the first order condition for $s$ is equivalent to

$$
S_{1}=\frac{\left(1-t^{E}\right)(1-\epsilon)(1-s-\alpha)}{1-s}-\frac{\left(1-t^{F}\right)(1-\alpha)(s-\epsilon)}{s}=0 .
$$

The second order condition is also satisfied, $\frac{d S_{1}}{d s}<0$. (A.5) and (8) imply

$$
1-s-\alpha>0, \quad s-\epsilon>0 .
$$

Both terms must be of the same sign to satisfy (A.5). Adding up yields $1>\alpha+\epsilon$ in line with (8). If both terms were negative, (8) would be violated. Condition (A.6) ensures that a higher $s$ raises the entrepreneur's effort but reduces managerial effort in (A.2).

The differential of (A.5) shows how taxes affect the profit share. Using $S_{2} \equiv-\frac{d S_{1}}{d s}>0$

$$
\hat{s}=-\frac{\left(1-t^{E}\right)(1-\epsilon)(1-s-\alpha)}{(1-s) s \cdot S_{2}} \cdot \hat{t}^{E}+\frac{\left(1-t^{F}\right)(1-\alpha)(s-\epsilon)}{s^{2} \cdot S_{2}} \cdot \hat{t}^{F} .
$$

A uniform tax has no effect on optimal profit sharing, $\hat{s}=-S_{1} /\left(s S_{2}\right) \cdot \hat{t}=0$ on account of (A.5). The tax cancels from both sides of the optimality condition. In this case, we can explicitely solve for the optimal profit share. From $S_{1}=0$, we obtain $(1-\epsilon) s \alpha=(1-s)[s \alpha+(1-s-\alpha) \epsilon]$. Exand by $+s \alpha \epsilon-s \alpha \epsilon$ and write the square bracket as $[(1-\epsilon) s \alpha+(1-s)(1-\alpha) \epsilon]$. We get $(1-\epsilon) \alpha s^{2}=(1-s)^{2}(1-\alpha) \epsilon$ or

$$
\frac{s^{2}}{(1-s)^{2}}=\frac{(1-\alpha) \cdot \epsilon}{\alpha \cdot(1-\epsilon)} \text {. }
$$

\section{B Income and Welfare}

Appendix B derives aggregate income and welfare. The entire population splits into $M$ agents endowed with managerial skills who can either be workers or VCs, while $1-M$ are endowed with variable entrepreneurial research skills. Out of the latter group, a part $1-M-R$ directly opts for employment in the old economy, and a part $R$ tries entrepreneurship in pursuing a seed investment. Only $E$ of them succeed to attract VC 
and start a firm while the $R-E$ unsuccessful ones turn back to employment, after having sunk a research effort and consumed a lump-sum research subsidy or grant $z^{R}$. All agents are subject to a per capita lump-sum tax $T$. Incomes of these different groups are

$$
\begin{aligned}
& 1-M-R: w-T, \quad M-F: w-T, \\
& E: Y^{E}+z^{R}-T, \quad F: \text { vf }(\theta) Y^{F}+z^{F}-T, \\
& R-E: w+z^{R}-T .
\end{aligned}
$$

Taking account of different average incomes, the government budget constraint is

$$
\begin{aligned}
& T+t^{E}[s p \pi+B] E+t^{F}\left[(1-s) p \pi-B-\left(1+t^{I}\right) I\right] E+t^{I} I E \\
& =G+z^{X} q x N+z^{F} F+z^{R} R .
\end{aligned}
$$

To compute aggregate income, multiply the income terms in (B.1) with the size of the population groups and add up. Using (9), (B.2), $\pi=\left(1+z^{X}\right) q x-x$ in (6) and $N=p E$ in (20) yields, after some manipulations,

$$
Y=w+[(q-1) x p-I-w] E-w F-G
$$

Equate spending $Y=V D+Z$ with aggregate income in (B.3). Spending on innovative goods is $V D=x^{D} q N$, where the superscript indicates the demand side as in (2). The wage rate is $w=1$, manufacturing supply $L=1-E-F$ by (13), and $N=p E$ by (20). The aggregate income spending identity thus implies Walras' Law which says that valued excess demands sum up to zero, $\left(x-x^{D}\right) N \cdot q+(L-I E-x N-G-Z)=0$. Demand for traditional goods stems from consumer demand $Z$, government $\mathrm{R} \& \mathrm{D}$ spending $G$, capital goods spending of $E$ start-ups and intermediate inputs of $N=p E$ mature firms in the innovative sector. By Walras' Law, market clearing for innovative goods, $x=x^{D}$, implies market clearing for traditional goods.

Indirect utility in (5), $U^{i *}=y^{i}-l^{i}+C$, depends on income, effort costs, and consumer surplus. Aggregate income is given in (B.3). Effort costs consist of productive efforts $e$ and $a$ and search efforts $\delta$ and $k^{i}$ by VCs and entrepreneurs, giving a total cost of $\gamma a E+\delta F$ by VCs and $\beta e E+K, K=\int_{0}^{R} k^{i} d i$, by entrepreneurs. Using (B.3) together 
with $w=1$ and (13), we have

$$
\begin{aligned}
U^{*} & =C(V)+1+S^{*} E-(\delta(v)+1) F-K-G, \\
S^{*} & =(q-1) x p-\beta e-\gamma a-I-1 .
\end{aligned}
$$

Note that $S^{*}$ is the social surplus from a new start-up, summing up the surplus derived by the VC, the entrepreneur and the government. This social surplus is different from the private one as defined in $(10) .{ }^{21}$

\section{Comparative Statics}

\section{C.1 Preliminaries}

This appendix computes the log-linearized form of the system in (23) and proves the results of section 3. In all policy scenarios, we restrict attention to a uniform capital gains tax $t=t^{E}=t^{F}$ and to zero entry subsidies $z^{R}=z^{F}=0$ in the initial equilibrium. Following the discussion in section 2.6, we must first relate joint surplus and the survival rate to sales of mature firms which stands for profits and thereby venture returns, $\hat{\pi}=\hat{x}$. Given uniform capital gains taxes, the profit share remains fixed by (A.8), i.e. $\hat{s}=0$. Therefore, efforts in (A.2) change proportionately and affect the firm's success rate by

$$
\hat{e}=\hat{a}=\frac{1}{1-\epsilon-\alpha}(\hat{x}-\hat{t}), \quad \hat{p}=\zeta_{P X} \cdot(\hat{x}-\hat{t}), \quad \zeta_{P X} \equiv \frac{\epsilon+\alpha}{1-\epsilon-\alpha} .
$$

The joint surplus (10) is $S=(1-t)\left[p \pi-\left(1+t^{I}\right) I\right]-\gamma a-\beta e-1$ and changes as

$$
\begin{aligned}
d S= & (1-t)\left[p \pi \cdot \hat{x}-\left(1+t^{I}\right) I \cdot \hat{t}^{I}\right]-(1-t)\left[p \pi-\left(1+t^{I}\right) I\right] \cdot \hat{t} \\
& +\left[(1-t) \pi p_{a}-\gamma\right] d a+\left[(1-t) \pi p_{e}-\beta\right] d e .
\end{aligned}
$$

Replace marginal effort costs $\beta$ and $\gamma$ by (11) and note $e p_{e} / p=\epsilon$ and $a p_{a} / p=\alpha$ by (8). The second line emerges as $(1-t) p \pi[s \alpha \hat{a}+(1-s) \epsilon \hat{e}]$. Substituting the elasticities into

\footnotetext{
${ }^{21}$ One may check that the social surplus results by adding net expected tax revenue per project in (10), $S^{*}=S+t^{E}[s p \pi+B]+t^{F}\left[(1-s) p \pi-B-\left(1+t^{I}\right) I\right]-z^{X} q x p+t^{I} I$.
} 
(C.2) shows how joint surplus relates to venture returns (i.e. sales) $x$ and taxes,

$$
\begin{aligned}
\hat{S} & =\frac{(1-t) p \pi \cdot \zeta_{S X}}{S} \cdot \hat{x}-\frac{I^{N}}{S} \cdot \hat{t}^{I}-\frac{(1-t) p \pi \cdot \zeta_{S X}-I^{N}}{S} \cdot \hat{t} \\
\zeta_{S X} & \equiv \frac{1-s \epsilon-(1-s) \alpha}{1-\epsilon-\alpha}>1, \quad I^{N} \equiv(1-t)\left(1+t^{I}\right) I .
\end{aligned}
$$

The log-linearized form of (23) becomes (use $\hat{q}=-\hat{z}^{X}$ in PM):

$$
\begin{aligned}
P M: & -\mu \hat{x}+\mu \lambda \hat{z}^{X} & =\hat{p}+\eta \hat{\theta}+\hat{v}+\hat{F}, \\
S R: & \hat{S}-(1-\eta) \hat{\theta} & =\kappa \cdot(\hat{\theta}+\hat{v}+\hat{F})-\left(\hat{G}+k^{-1} \hat{z}^{R}\right), \\
S F: & \hat{S}+\eta \hat{\theta} & =\omega \hat{v}, \\
F E: & \hat{\Omega} & =\hat{S}+\eta \hat{\theta}+\hat{v}-\frac{(1+\omega) \delta}{1+\delta} \hat{v}+\frac{1}{1+\delta} \hat{z}^{F}=0 .
\end{aligned}
$$

In the condition SR for seed investments, we assume $z^{R}=0$ prior to the shock and note that $\tilde{\xi}=\xi$ remains constant when capital gains taxes are uniform. Linearization of SR thus yields $\hat{k}-(1 / k) \hat{z}^{R}=\hat{S}+\hat{f}-\hat{\theta}$. Using (15), $\hat{k}=\kappa \hat{R}-\hat{G}$, and noting $\hat{R}=\hat{\theta}+\hat{v}+\hat{F}$ gives the result for SR. Next, the condition SF results upon using the constant elasticity form noted in (18), where $v \delta^{\prime \prime} / \delta^{\prime}=\omega$ and $v \delta^{\prime} / \delta=1+\omega$, giving $\hat{\delta}^{\prime}=\omega \hat{v}$. Finally, the free entry condition FE is evaluated at $z^{F}=0$ and $\Omega=0$, implying $(1-\xi) S f(\theta) v=\delta+1$. Defining $\hat{\Omega} \equiv d \Omega /(\delta+1)$ and using $v \delta^{\prime} / \delta=1+\omega$, gives the last result in (C.4).

To prepare the welfare evaluation, one needs the derivatives of the welfare measure in (B.4). To this end, we obtain an alternative expression for aggregate welfare by substituting consumer surplus (5) and using $V D=N q x$ and $K(R, G)=\int_{0}^{R} k(i, G) d i$,

$$
\begin{aligned}
U^{*} & =1+u(D)-x p(e, a) E-(\beta e+\gamma a+I+1) E-(1+\delta(v)) F-K-G, \\
D & =N^{\rho} x, \quad V=N^{1-\rho} q, \quad N=p(e, a) E, \quad E=f(\theta) v F, \quad \theta=R /(v F) .
\end{aligned}
$$

For convenience, we repeat the relevant relationsships showing how the composite good $D$ and the number $E$ of start-ups and $N$ of mature firms depend on other variables. Take 
the derivatives with respect to $x, e, a, v ; R, F, G$ and use $u^{\prime}(D)=V=N^{1-\rho} q$ :

$$
\begin{aligned}
& \text { (a) } \partial U^{*} / \partial x=(q-1) N \text {, } \\
& \text { (b) } \partial U^{*} / \partial e=\left[(q \rho-1) x p_{e}-\beta\right] E \text {, } \\
& \text { (c) } \partial U^{*} / \partial a=\left[(q \rho-1) x p_{a}-\gamma\right] E \text {, } \\
& \text { (d) } \partial U^{*} / \partial v=S^{*} \cdot \partial E / \partial v-\delta^{\prime}(v) F \text {, } \\
& \text { (e) } \partial U^{*} / \partial R=S^{*} \cdot \partial E / \partial R-k(R, G) \text {, } \\
& \text { (f) } \partial U^{*} / \partial F=S^{*} \cdot \partial E / \partial F-\delta(v)-1, \\
& \text { (g) } \partial U^{*} / \partial G=K_{G}-1, \quad K_{G} \equiv-\int_{0}^{R} k_{G}(i, G) d i \text {, } \\
& \text { (h) } \quad S^{*}=(q \rho-1) x p-\beta e-\gamma a-I-1 \text {. }
\end{aligned}
$$

After some manipulations, these derivatives yield the welfare differential

$$
\begin{aligned}
d U^{*} & =\left(K_{G}-1\right) G \cdot \hat{G}+(q-1) x N \cdot \hat{x}+(q-1) \rho x N \cdot \hat{p} \\
& +[1-(1-t) s] \pi N \epsilon \cdot \hat{e}+[1-(1-t)(1-s)] \pi N \alpha \cdot \hat{a} \\
& +\left[\eta S^{*}-\xi S\right] \frac{f(\theta)}{\theta} R \cdot \hat{R}+\left[(1-\eta) S^{*}-(1-\xi) S\right] E \cdot(\hat{v}+\hat{F}) .
\end{aligned}
$$

The third to fifth terms follow after expanding $q \rho-1=(q-1) \rho+\rho-1$ in (C.6.b,c), using $\pi=(\rho-1) x$, replacing effort costs $\beta, \gamma$ from (11) and noting $e p_{e}=\epsilon p$ and $a p_{a}=\alpha p$ as well as $\hat{p}=\epsilon \hat{e}+\alpha \hat{a}$ and $N=p E$. In the third line, the first term follows from (C.6.e) upon substituting $k=S \xi f / \theta$ from (17) and $d E / d R=f^{\prime}$ and using (15). The coefficient of $\hat{v}$ similarly derives from (C.6.d) upon substituting $\delta^{\prime}$ from (19). Finally, the effect of $\hat{F}$ relies on the assumption that the initial equilibrium is one with zero profits and a zero entry subsidy, $\Omega=0$ and $z^{F}=0$, so that $(1-\xi) S \cdot f(\theta) v=\delta+1$. The wedges in the third line relate to matching externalities that arise whenever the matching productivity of each side as measured by the elasticity $\eta$ is not well aligned with its bargaining power $(\xi \neq \eta)$ and the social surplus from a match is different from the private surplus $\left(S \neq S^{*}\right)$. However, $S=S^{*}$ in the untaxed laissez-faire equilibrium, as was mentioned in the context of (B.4). 


\section{C.2 Short-Run Equilibrium}

The comparative statics of the short-run equilibrium is defined by PM, SR and SF in (C.4). The number of VCs is fixed but they may finance and advise a variable number of portfolio companies. To prepare for long-run results, it is insightful to consider also the impact of an exogenous entry $\hat{F}$ of VCs. The solution first solves for the intersection $\theta(x)$ and $v(x)$ of the supply and demand curves for $\mathrm{VC}$ defined by the search conditions SR and SF, taking venture returns $x$ as given. Figure 2 illustrates. The next step solves the product market condition PM to obtain equilibrium returns $x$. With joint surplus uniquely related to venture returns by (C.3), VC market equilibrium yields

$$
\begin{aligned}
\hat{\theta} & =\frac{1}{\Delta_{S}}\left[(\omega-\kappa) \hat{S}+\omega\left(\hat{G}+k^{-1} \hat{z}^{R}\right)-\omega \kappa \hat{F}\right] \\
\hat{v} & =\frac{1}{\Delta_{S}}\left[(1+\kappa) \hat{S}+\eta\left(\hat{G}+k^{-1} \hat{z}^{R}\right)-\eta \kappa \hat{F}\right] \\
\eta \hat{\theta}+\hat{v} & =\frac{1}{\Delta_{S}}\left[(1+\kappa+(\omega-\kappa) \eta) \hat{S}+(1+\omega) \eta\left(\hat{G}+k^{-1} \hat{z}^{R}-\kappa \hat{F}\right)\right], \\
\Delta_{S} & \equiv(1-\eta+\kappa) \omega+\kappa \eta>0 .
\end{aligned}
$$

We largely focus on the case $\omega>\kappa$ where the elasticity $\omega$ of marginal search cost with respect to search intensity of VCs exceeds the elasticity $\kappa$ of see investment cost $k$ with respect to entrepreneurial entry. This is justified by the limit case of perfectly elastic supply of entrepreneurs where $\kappa=0$ and entry cost is the same for the entire population such that $k=k_{0} / G$ in (16). With entrepreneurial entry being more elastic than $\mathrm{VC}$ supply, an increase in the joint surplus of start-up firms attracts relatively more seed investments and creates more demand for $\mathrm{VC}$ as compared to additional financing offers $v$. The market for $\mathrm{VC}$ thus becomes increasingly tight and $\theta=R / v F$ increases as in (C.8). The third line shows that VC portfolio size $v f(\theta)$ expands when projects become more profitable on account of a higher joint surplus.

At this stage, we know how venture returns or profits, as implied by sales $x$, affect efforts and the success rate, joint surplus, market tightness and $\mathrm{VC}$ search intensity. Using (C.1,3,8) in condition PM in (C.4), $\hat{N}=\hat{p}+\eta \hat{\theta}+\hat{v}+\hat{F}$, one finds how venture returns 
determine the supply of mature firms. Collecting terms and using $\Delta_{S}$ gives

$$
\begin{aligned}
\hat{N} & =\left[\zeta_{P X}+\frac{1+\kappa+(\omega-\kappa) \eta}{\Delta_{S}} \frac{(1-t) p \pi \cdot \zeta_{S X}}{S}\right] \hat{x}-\left[\zeta_{P X}+\frac{1+\kappa+(\omega-\kappa) \eta}{\Delta_{S}} \frac{(1-t) p \pi \cdot \zeta_{S X}-I^{N}}{S}\right] \hat{t} \\
& -\frac{1+\kappa+(\omega-\kappa) \eta}{\Delta_{S}} \frac{I^{N}}{S} \hat{t}^{I}+\frac{(1+\omega) \eta}{\Delta_{S}}\left(\hat{G}+k^{-1} \hat{z}^{R}\right)+\frac{(1-\eta)(1+\kappa) \omega}{\Delta_{S}} \hat{F} .
\end{aligned}
$$

This equation defines, in log-linearized form, an upward sloping supply curve of new goods. The left hand side of PM in (C.4) states the demand curve for product variety, $\hat{N}=-\mu \hat{x}+\mu \lambda \hat{z}^{X}$. Figure 3 illustrates. The intersection yields scale and variety of innovative goods or, equivalently, venture returns and the number of mature firms in product market equilibrium. Formally,

$$
\hat{x}=\zeta_{t} \hat{t}+\zeta_{I} \hat{t}^{I}+\zeta_{x} \hat{z}^{X}-\zeta_{G}\left(\hat{G}+k^{-1} \hat{z}^{R}\right)-\zeta_{F} \hat{F}, \quad \hat{N}=-\mu \hat{x}+\mu \lambda \hat{z}^{X}
$$

All $\zeta$-coefficients are defined positive. The term $\Delta_{X}$ stands for the elasticity of excess demand for variety with respect to venture returns,

$$
\begin{array}{rlrl}
\Delta_{X} & \equiv \mu+\zeta_{P X}+\frac{1+\kappa+(\omega-\kappa) \eta}{\Delta_{S}} \frac{(1-t) p \pi \cdot \zeta_{S X}}{S}, & \mu \equiv & {[(1-\lambda) \rho+\lambda]^{-1}>0} \\
\zeta_{t} \equiv \frac{\zeta_{P X}}{\Delta_{X}}+\frac{1+\kappa+(\omega-\kappa) \eta}{\Delta_{X} \Delta_{S}} \frac{(1-t) p \pi \cdot \zeta_{S X}-I^{N}}{S}, & \zeta_{I} \equiv & \frac{1+\kappa+(\omega-\kappa) \eta}{\Delta_{X} \Delta_{S}} \frac{I^{N}}{S} \\
\zeta_{G} \equiv \frac{(1+\omega) \eta}{\Delta_{X} \Delta_{S}}, \quad \zeta_{X} \equiv \frac{\mu \lambda}{\Delta_{X}}, & \zeta_{F} \equiv & \frac{(1-\eta)(1+\kappa) \omega}{\Delta_{X} \Delta_{S}}
\end{array}
$$

To see how the tax affects efforts in (C.1), one requires $\hat{x}-\hat{t}=\left(\zeta_{t}-1\right) \hat{t}$, where

$$
1-\zeta_{t}=\frac{\mu}{\Delta_{X}}+\frac{1+\kappa+(\omega-\kappa) \eta}{\Delta_{X} \Delta_{S}} \cdot \frac{I^{N}}{S}>0
$$

A key result is the policy impact on VC search intensity which importantly depends on joint surplus. Replacing $\hat{x}$ in (C.3) by (C.10) yields

$$
\begin{aligned}
\hat{S}= & -\frac{\left(\mu+\zeta_{P X}\right) I^{N}}{S \Delta_{X}} \hat{t}^{I}-\frac{\mu\left[(1-t) p \pi \cdot \zeta_{S X}-I^{N}\right]-\zeta_{P X} I^{N}}{S \Delta_{X}} \hat{t} \\
& +\frac{(1-t) p \pi \cdot \zeta_{S X}}{S}\left[\zeta_{x} \hat{z}^{X}-\zeta_{G}\left(\hat{G}+k^{-1} \hat{z}^{R}\right)-\zeta_{F} \hat{F}\right] .
\end{aligned}
$$

The coefficient of $\hat{t}^{I}$ is $\frac{(1-t) p \pi \cdot \zeta_{S X}}{S} \zeta_{I}-\frac{I^{N}}{S}=-\frac{\left(\mu+\zeta_{P X}\right)}{\Delta_{X}} \frac{I^{N}}{S}$ which follows from some manipulations after substituting $\zeta_{I}$ and using $\Delta_{X}$. Further, the coefficient for $\hat{t}$ is $\frac{\left(\zeta_{t}-1\right)(1-t) p \pi \cdot \zeta_{S X}+I^{N}}{S}$ and emerges as in (C.12) upon substitution of $\zeta_{t}-1$ and further manipulations using $\Delta_{X}$. The tax rate reduces joint surplus if the elasticity $\mu$ of variety demand is large. 
Using $\hat{S}$ in (C.8), we find that the only ambiguous effect on search intensity comes from $\hat{G}+k^{-1} \hat{z}^{R}$. Substitute $\zeta_{G}$ and use $\Delta_{X}$ and $\Delta_{S}$ and get, after some manipulations,

$$
\begin{aligned}
\hat{v} & =\frac{1}{\Delta_{S}}\left[(1+\kappa) \hat{S}+\eta\left(\hat{G}+k^{-1} \hat{z}^{R}\right)\right] \\
& =\left[\mu+\zeta_{P X}-\frac{(1-t) p \pi \cdot \zeta_{S X}}{S}\right] \frac{\eta}{\Delta_{S} \Delta_{X}}\left(\hat{G}+k^{-1} \hat{z}^{R}\right) \gtrless 0 .
\end{aligned}
$$

Entrepreneurship changes by $\hat{R}=\hat{\theta}+\hat{v}+\hat{F}$. Substituting from (C.8),

$$
\hat{R}=\frac{1}{\Delta_{S}}\left[(1+\omega) \hat{S}+(\omega+\eta)\left(\hat{G}+k^{-1} \hat{z}^{R}\right)+(1-\eta) \omega \hat{F}\right] .
$$

\section{C.3 Long-Run Equilibrium}

To link the short and long-run effects, one must show first how policy shocks create rents $\Omega$ on VC investing for a given number of VCs $F$ and, second, how entry $\hat{F}$ eliminates rents to determine a long-run number of VCs (free entry). Substituting SF in FE in (C.4), one finds that policy creates rents whenever it boosts $\mathrm{VC}$ search intensity $\hat{v}$,

$$
\hat{\Omega}=\frac{1}{1+\delta}\left[(1+\omega) \hat{v}+\hat{z}^{F}\right]=0 \quad \Rightarrow \quad \hat{v}=-\frac{1}{1+\omega} \hat{z}^{F}
$$

If a policy raises search intensity it creates rents and thereby eventually attracts more VCs, $\hat{F}>0$. As entry continues, rents get eroded until no further entry is profitable. We now show that an exogenous increase in $F$ reduces individual search intensity and shortrun rents to VC investing. Consider (C.4). For any given market tightness and search intensity, the supply curve for VC shifts to the right since more VCs are able to finance more firms. As Figure 2 indicates, market tightness and equilibrium search intensity both decline to equilibrate the market for VC, see (C.8). The implied reduction in portfolio size retards the initial supply expansion and stops the decline in venture returns. On net, VC entry boosts the number of mature firms and thereby erodes venture returns by $\hat{x}=-\zeta_{F} \hat{F}$ as in (C.10). Figure 3 illustrates. Since both effects $\hat{F}>0>\hat{S}$ reduce search intensity, we have shown that $\mathrm{VC}$ entry reduces rents in (C.16). If a policy boosts search intensity and VC rents in the short-run, it triggers entry of VCs. Increasing competition reduces the returns to search and discourages new investments until rents are finally exhausted and 
the long-run search intensity attains the value in (C.16). Quite intuitively, a higher entry subsidy reduces the net opportunity $\operatorname{cost} 1-z^{F}$ of a VC such that a smaller portfolio is required to break even. Search intensity is reduced in the long-run.

Next, the investment conditions determine market tightness and joint surplus of startups although the number of VCs is not yet known and must be inferred from the product market condition. Solving SR and SF in (C.4) in terms of $\hat{v}$ yields the solution for the required surplus and market tightness,

$$
\begin{aligned}
& \hat{\theta}=\frac{1}{1+\kappa}\left[\left(\hat{G}+k^{-1} \hat{z}^{R}\right)-\kappa \hat{F}+(\omega-\kappa) \hat{v}\right], \\
& \hat{S}=\frac{\Delta_{S}}{1+\kappa} \hat{v}-\frac{\eta}{1+\kappa}\left(\hat{G}+k^{-1} \hat{z}^{R}\right)+\frac{\kappa \eta}{1+\kappa} \hat{F} .
\end{aligned}
$$

By (C.3), to sustain this surplus, the necessary venture returns must amount to

$$
\begin{aligned}
\hat{x} & =\frac{S}{(1-t) p \pi \cdot \zeta_{S X}}\left[\frac{I^{N}}{S} \hat{t}^{I}+\frac{(1-t) p \pi \cdot \zeta_{S X}-I^{N}}{S} \hat{t}\right] \\
& +\frac{S}{(1-t) p \pi \cdot \zeta_{S X}}\left[\frac{\Delta_{S}}{1+\kappa} \hat{v}-\frac{\eta}{1+\kappa}\left(\hat{G}+k^{-1} \hat{z}^{R}\right)+\frac{\kappa \eta}{1+\kappa} \hat{F}\right] .
\end{aligned}
$$

Now get $\hat{F}$ from product market condition, $\mu \lambda \hat{z}^{X}=\left(\mu+\zeta_{P X}\right) \hat{x}+\eta \hat{\theta}+\hat{v}+\hat{F}-\zeta_{P X} \hat{t}$, after substituting the results for $\hat{\theta}$ and $\hat{x}$ :

$$
\begin{aligned}
\nabla_{F} \cdot \hat{F} & =\mu \lambda \cdot \hat{z}^{X}-\frac{\left(\mu+\zeta_{P X}\right) I^{N}}{(1-t) p \pi \cdot \zeta_{S X}} \cdot \hat{t}^{I} \\
& -\frac{\mu\left[(1-t) p \pi \cdot \zeta_{S X}-I^{N}\right]-\zeta_{P X} I^{N}}{(1-t) p \pi \cdot \zeta_{S X}} \cdot \hat{t} \\
& +\frac{\mu+\zeta_{P X}-(1-t) p \pi \cdot \zeta_{S X} / S}{(1-t) p \pi \cdot \zeta_{S X} / S} \frac{\eta}{1+\kappa} \cdot\left(\hat{G}+k^{-1} \hat{z}^{R}\right) \\
& -\left[\frac{1+\kappa+(\omega-\kappa) \eta}{1+\kappa}+\frac{\left(\mu+\zeta_{P X}\right) S}{(1-t) p \pi \cdot \zeta_{S X}} \frac{\Delta_{S}}{1+\kappa}\right] \cdot \hat{v}, \\
\nabla_{F} & \equiv \frac{1+(1-\eta) \kappa}{1+\kappa}+\frac{\left(\mu+\zeta_{P X}\right) S}{(1-t) p \pi \cdot \zeta_{S X}} \frac{\eta \kappa}{1+\kappa}>0 .
\end{aligned}
$$

At first sight, the coefficients of $\hat{t}$ and $\hat{G}+k^{-1} \hat{z}^{R}$ are ambiguous which is a mirror image of the short-run ambiguity in search intensity and VC rents, see (C.13-14). The short-run effect of the tax rate on search intensity and VC rents and, thereby, on long-run VC entry is negative if the demand elasticity $\mu$ of new goods with respect to venture returns $x$ is large. This condition is met if the demand elasticity of the final good is large but satisfies $\lambda<\sigma$, see (4). ${ }^{22}$ If $\mu$ is sufficiently large, the coefficient of $\hat{G}$ is positive as well so that the tax reduces VC entry while more R\&D spending and research grants for seed investments raise it in the long-run.

\footnotetext{
${ }^{22}$ Note that $\mu>0$ requires $\lambda<\sigma$ where the upper bound $\sigma>1$. If $\lambda \rightarrow \sigma$ from below, $\mu \rightarrow \infty$.
} 
Output Subsidy: Setting $\hat{v}=0$ as in (C.16) and taking the product market clearing number of VCs from (C.19), $\hat{F}=\frac{\mu \lambda}{\nabla_{F}} \hat{z}^{X}>0$, one derives from (C.17-18)

$$
\begin{aligned}
& \hat{S}=\frac{\kappa \eta}{1+\kappa} \hat{F}>0, \quad \hat{x}=\frac{S}{(1-t) p \pi \cdot \zeta_{S X}} \frac{\kappa \eta}{1+\kappa} \hat{F}>0, \\
& \hat{\theta}=-\frac{\kappa}{1+\kappa} \hat{F}<0, \quad \hat{E}=\hat{\theta}+\hat{v}+\hat{F}=\frac{1}{1+\kappa} \hat{F}>0 .
\end{aligned}
$$

Subsidizing VC Entry: The first line below results from (C.16) and (C.19). The second is shown after some manipulations by substituting (C.19) into (C.17). The effect on $\hat{x}$ follows from inverting (C.3) and noting the impact on $\hat{S}$. Lastly, the impact on $\hat{\theta}$ follows from (C.8) and the signs of $\hat{S}$ and $\hat{F}$ :

$$
\begin{aligned}
& \hat{v}=-\frac{1}{1+\omega} \hat{z}^{F}<0, \quad \hat{F}=-\frac{1}{\nabla_{F}}\left[\frac{1+\kappa+(\omega-\kappa) \eta}{1+\kappa}+\frac{\left(\mu+\zeta_{P X}\right) S}{(1-t) p \pi \cdot \zeta_{S X}} \frac{\Delta_{S}}{1+\kappa}\right] \hat{v}>0, \\
& \hat{S}=\frac{1}{1+\kappa}\left[\Delta_{S} \hat{v}+\eta \kappa \hat{F}\right]=\frac{(1-\eta) \omega}{\nabla_{F}} \hat{v}<0, \\
& \hat{x}=\frac{S}{(1-t) p \pi \cdot \zeta_{S X}} \hat{S}<0, \quad \hat{N}=-\mu \hat{x}>0, \quad \hat{\theta}=\frac{1}{\Delta_{S}}[(\omega-\kappa) \hat{S}-\omega \kappa \hat{F}]>0 .
\end{aligned}
$$

Research Policy: The first line results from (C.16) and (C.19), with $\hat{F}>0$ for $\mu$ large. The square brackets in (C.14) and (C.19) are identical so that the sign of the short-run effect on $\hat{v}$ is the same as the sign of the long-run effect on VC entry $\hat{F}$. Substituting $\hat{F}$ from the first line of (C.22) and using the definition of $\nabla_{F}$, one obtains after some manipulations $\hat{G}+k^{-1} \hat{z}^{R}-\kappa \hat{F}=\left(\hat{G}+k^{-1} \hat{z}^{R}\right) / \nabla_{F}$. Using this result in (C.17-18) yields the second and third lines where $\hat{N}$ simply reflects the product demand curve:

$$
\begin{aligned}
& \hat{v}=0, \quad \hat{F}=\frac{\left[\mu+\zeta_{P X}-(1-t) p \pi \zeta_{S X} / S\right] \eta}{\nabla_{F}(1+\kappa)(1-t) p \pi \zeta_{S X} / S}\left(\hat{G}+k^{-1} \hat{z}^{R}\right) \gtrless 0, \\
& \hat{x}=-\frac{S}{(1-t) p \pi \zeta_{S X}} \frac{\eta}{1+\kappa} \frac{1}{\nabla_{F}}\left(\hat{G}+k^{-1} \hat{z}^{R}\right)<0, \quad \hat{N}=-\mu \hat{x}>0, \\
& \hat{S}=-\frac{\eta}{1+\kappa} \frac{1}{\nabla_{F}}\left(\hat{G}+k^{-1} \hat{z}^{R}\right)<0, \quad \hat{\theta}=\frac{1}{1+\kappa} \frac{1}{\nabla_{F}}\left(\hat{G}+k^{-1} \hat{z}^{R}\right)>0 .
\end{aligned}
$$

Self-financed Tax Cut: Free entry implies $\hat{v}=0$. Starting from an untaxed equilibrium and imposing the budget restriction $I \cdot \hat{t}^{I}=-(p \pi-I) \cdot \hat{t}$ on $(\mathrm{C} .19)$, one gets

$$
\hat{F}=-\frac{\left[\left(\zeta_{S X}-1\right) \mu-\zeta_{P X}\right]}{\zeta_{S X} \nabla_{F}} \cdot \hat{t}>0 .
$$

Again, the number of VCs increases if the demand elasticity $\mu$ is large enough. Since $\hat{v}=0$, entry of VCs reduces market tightness and raises joint surplus in the long-run, see 
(C.17). Venture returns emerge after imposing the budget restriction on (C.18) and some tedious manipulations:

$$
\begin{aligned}
\hat{x} & =\frac{\zeta_{S X}-1}{\zeta_{S X}} \cdot \hat{t}+\frac{S}{p \pi \zeta_{S X}} \frac{\kappa \eta}{1+\kappa} \hat{F}=\frac{\left(\zeta_{S X}-1\right)[1+(1-\eta) \kappa]+\zeta_{P X} \kappa \eta S /(p \pi)}{(1+\kappa) \zeta_{S X} \nabla_{F}} \hat{t}<0, \\
\hat{x}-\hat{t} & =\frac{-1}{\zeta_{S X}} \cdot \hat{t}+\frac{S}{p \pi \zeta_{S X}} \frac{\kappa \eta}{1+\kappa} \cdot \hat{F}>0 .
\end{aligned}
$$

\section{References}

[1] Aghion, Philippe and Jean Tirole (1994), The Management of Innovation, Quarterly Journal of Economics 109, 1185-1209.

[2] Audretsch, David B., Erik E. Lehmann and Susanne Warning (2003), University Spillovers: Strategic Location and New firm Performance, CEPR DP 3837.

[3] Bascha, Andreas and Uwe Walz (2001), Convertible Securities and Optimal Exit Decisions in Venture Capital Finance, Journal of Corporate Finance 7, 285-306.

[4] Becker, Ralf and Thomas Hellmann (2002), The Genesis of Venture Capital - Lessons from the German Experience, in: Vesa Kanniainen and Christian Keuschnigg (eds.), Venture Capital, Entrepreneurship and Public Policy, CESifo Seminar Series, MIT Press, forthcoming.

[5] Bergemann, Dirk and Ulrich Hege (1998), Venture Capital Financing, Moral Harzard and Learning, Journal of Banking and Finance 104, 703-735.

[6] Bergloef, Eric (1994), A Control Theory of Venture Capital Finance, Journal of Law, Economics and Organization 10, 247-267.

[7] Boadway, Robin and Jean-François Tremblay (2002), Public Economics and Startup Entrepreneurs, in: Vesa Kanniainen and Christian Keuschnigg (eds.), Venture Capital, Entrepreneurship and Public Policy, CESifo Seminar Series, MIT Press, forthcoming.

[8] Botazzi, Laura and Marco Da Rin (2002), Venture Capital in Europe and the Financing of Innovative Companies, Economic Policy 34, 231-269.

[9] Casamatta, Catherine (2003), Financing and Advising: Optimal Financial Contracts With Venture Capitalists, Journal of Finance, forthcoming.

[10] Cullen, July Berry and Roger H. Gordon (2002), Taxes and Entrepreneurial Activity: Theory and Evidence for the U.S., NBER DP 9015.

[11] Cumming, Douglas and Jeffrey G. MacIntosh (2002), A Cross Country Comparison of Full and Partial Venture Capital Exits, Journal of Banking and Finance, forthcoming. 
[12] Diamond, Peter (1990), Pairwise Credit in Search Equilibrium, Quarterly Journal of Economics 105, 285-319.

[13] Dixit, Avinash K. and Joseph E. Stiglitz (1977), Monopolistic Competition and Optimum Product Variety, American Economic Review 67,297-308.

[14] European Commission (1994), Green Paper on Innovation, Brussels.

[15] European Commission (1998), Risk Capital: A Key to Job Creation in the European Union, Brussels.

[16] Gompers, Paul A. (1995), Optimal Investments, Monitoring, and the Staging of Venture Capital, Journal of Finance 50, 1461-1489.

[17] Gompers, Paul A. and Josh P. Lerner (1998), What Drives Venture Capital Fundraising?, Brookings Papers on Economic Activity - Microeconomics, 149-192.

[18] Gompers, Paul A. and Josh P. Lerner (1999), The Venture Capital Cycle, Cambridge: MIT Press.

[19] Gordon, Roger H. (1998), Can High Personal Tax Rates Encourage Entrepreneurial Activity?, IMF Staff Papers 45, 49-80.

[20] Gromb, Denis and David Scharfstein (2002), Entrepreneurship in Equilibrium, NBER DP 9001.

[21] Hart, Oliver (2001), Financial Contracting, Journal of Economic Literature 39, 10791100 .

[22] Hellmann, Thomas (1998), The Allocation of Control Rights in Venture Capital Contracts, Rand Journal of Economics 29, 57-76.

[23] Hellmann, Thomas and Manju Puri (2000), The Interaction Between Product Market and Financing Strategy: The Role of Venture Capital, Review of Financial Studies 13, 995-984.

[24] Hellmann, Thomas and Manju Puri (2002), Venture Capital and the Professionalization of Start-Up Firms, Journal of Finance 57, 169-197.

[25] Hosios, Arthur J. (1990), On the Efficiency of Matching and Related Models of Search and Unemployment, Review of Economic Studies 57, 279-298.

[26] Inderst, Roman and Holger M. Mueller (2003), The Effect of Capital Market Characteristics on the Value of Start-Up Firms, Journal of Financial Economics, forthcoming.

[27] Kaplan, Steven N. and Per Strömberg (2001), Venture Capitalists as Principals: Contracting, Screening, and Monitoring, American Economic Review 91, 426-430. 
[28] Kaplan, Steven N. and Per Strömberg (2003), Financial Contracting Theory Meets the Real World: An Empirical Analysis of Venture Capital Contracts, Review of Economic Studies 70, 281-315.

[29] Keuschnigg, Christian (2002), Taxation of a Venture Capitalist With a Portfolio of Firms, Oxford Economic Papers, forthcoming.

[30] Keuschnigg, Christian and Soren B. Nielsen (2003a), Tax Policy, Venture Capital and Entrepreneurship, Journal of Public Economics 87, 175-203.

[31] Keuschnigg, Christian and Soren B. Nielsen (2003b), Start-ups, Venture Capitalists and the Capital Gains Tax, Journal of Public Economics, forthcoming.

[32] Kortum, Samuel and Josh Lerner (2000), Assessing the Contribution of Venture Capital to Innovation, Rand Journal of Economics 31, 674-692.

[33] Lerner, Josh P. (2002), When Bureaucrates Meet Entrepreneurs: The Design of Effective 'Public Venture Capital' Programmes, Economic Journal 112, 557-572.

[34] Michelacci, Claudio and Javier Suarez (2002), Business Creation and the Stock Market, Review of Economic Studies, forthcoming.

[35] Neher, Darwin V. (1999), Staged Financing: An Agency Perspective, Review of Economic Studies 66, 255-274.

[36] Poterba, James M. (1989a), Capital Gains Tax Policy Toward Entrepreneurship, National Tax Journal 42, 375-389.

[37] Poterba, James M. (1989b), Venture Capital and Capital Gains Taxation, in: Lawrence, H.S. (eds), Tax Policy and the Economy, Vol. 3, Cambridge: MIT Press, 47-67.

[38] Repullo, Rafael and Javier Suarez (1999), Venture Capital Finance: A Security Design Approach, CEPR DP 2097.

[39] Rosen, Harvey S. (2002), Entrepreneurship and Taxation: Empirical Evidence, in: Vesa Kanniainen and Christian Keuschnigg (eds.), Venture Capital, Entrepreneurship and Public Policy, CESifo Seminar Series, MIT Press, forthcoming.

[40] Schmidt, Klaus M. (2003), Convertible Securities and Venture Capital Finance, Journal of Finance 43, 1139-1166.

[41] Tirole, Jean (2001), Corporate Governance, Econometrica 69, 1-35.

[42] Zucker, Lynne G., Michael R. Darby and Marilynn B. Brewer (1998), Intellectual Human Capital and the Birth of U.S. Biotechnology Enterprises, American Economic Review 88, 290-306. 


\section{CESifo Working Paper Series}

(for full list see www.cesifo.de)

1002 Matthew Clarke and Sardar M. N. Islam, Health Adjusted GDP (HAGDP) Measures of the Relationship Between Economic Growth, Health Outcomes and Social Welfare, July 2003

1003 Volker Grossmann, Contest for Attention in a Quality-Ladder Model of Endogenous Growth, August 2003

1004 Marcel Gérard and Joan Martens Weiner, Cross-Border Loss Offset and Formulary Apportionment: How do they affect multijurisdictional firm investment spending and interjurisdictional tax competition?, August 2003

1005 Burkhard Heer, Nonsuperneutrality of Money in the Sidrauski Model with Heterogeous Agents, August 2003

1006 V. Anton Muscatelli, Piergiovanna Natale, and Patrizio Tirelli, A Simple and Flexible Alternative to the Stability and Growth Pact Deficit Ceilings. Is it at hand?, August 2003

1007 Reto Foellmi and Josef Zweimüller, Inequality and Economic Growth: European Versus U.S. Experiences, August 2003

1008 James S. Costain and Michael Reiter, Business Cycles, Unemployment Insurance, and the Calibration of Matching Models, August 2003

1009 Marco Runkel, Optimal Contest Design when the Designer's Payoff Depends on Competitive Balance, August 2003

1010 Donald O. Parsons, Torben Tranaes and Helene Bie Lilleør, Voluntary Public Unemployment Insurance, August 2003

1011 Rüdiger Pethig and Andreas Wagener, Profit Tax Competition and Formula Apportionment, August 2003

1012 Johan Willner, Privatisation and Public Ownership in Finland, August 2003

1013 Seppo Kari and Jouko Ylä-Liedenpohja, Taxation and Valuation of International Real Investments, August 2003

1014 James Heckman, Rosa Matzkin and Lars Nesheim, Simulation and Estimation of Hedonic Models, August 2003

1015 Biswa N. Bhattacharyay, Towards a Macro-Prudential Leading Indicators Framework for Monitoring Financial Vulnerability, August 2003 
1016 J. Stephen Ferris and Stanley L. Winer, Searching for Keynes: With Application to Canada, 1870-2000, August 2003

1017 Massimo Bordignon, Luca Colombo and Umberto Galmarini, Fiscal Federalism and Endogenous Lobbies' Formation, August 2003

1018 Annette Alstadsæter, The Dual Income Tax and Firms' Income Shifting through the Choice of Organizational Form and Real Capital Investments, August 2003

1019 Peter Fredriksson and Bertil Holmlund, Optimal Unemployment Insurance Design: Time Limits, Monitoring, or Workfare?, August 2003

1020 Kashif S. Mansori, Following in their Footsteps: Comparing Interest Parity Conditions in Central European Economies to the Euro Countries, August 2003

1021 Christoph Borgmann and Matthias Heidler, Demographics and Volatile Social Security Wealth: Political Risks of Benefit Rule Changes in Germany, August 2003

1022 Kjell Erik Lommerud, Bjørn Sandvik and Odd Rune Staume, Good Jobs, Bad Jobs and Redistribution, August 2003

1023 Patrick Karl O'Brien, The Governance of Globalization: The Political Economy of Anglo-American Hegemony, 1793-2003, September 2003

1024 Antonio Ciccone and Giovanni Peri, Skills' Substitutability and Technological Progress: U.S. States 1950-1990, September 2003

1025 Bjørn Sandvik, Optimal Taxation and Normalisations, September 2003

1026 Massimo Bordignon and Gilberto Turati, Bailing Out Expectations and Health Expenditure in Italy, September 2003

1027 José A. Herce, Namkee Ahn, Ricard Génova, and Joaquín Pereira, Bio-Demographic and Health Aspects of Ageing in the EU, September 2003

1028 John Komlos and Marieluise Baur, From the Tallest to (One of) the Fattest: The Enigmatic Fate of the American Population in the $20^{\text {th }}$ Century, September 2003

1029 Stefan Napel and Mika Widgrén, Bargaining and Distribution of Power in the EU's Conciliation Committee, September 2003

1030 Kai Li and Dale J. Poirier, Relationship Between Maternal Behavior During Pregnancy, Birth Outcome, and Early Childhood Development: An Exploratory Study, September 2003

1031 Ivar Ekeland, James J. Heckman, and Lars Nesheim, Identifcation and Estimation of Hedonic Models, September 2003

1032 Kjetil Bjorvatn and Alexander W. Cappelen, Decentralization and the Fate of Minorities, September 2003 
1033 Lars-Erik Borge and Jørn Rattsø, The Relationships Between Costs and User Charges: The Case of a Norwegian Utility Service, September 2003

1034 Maureen Were and Nancy N. Nafula, An Assessment of the Impact of HIV/AIDS on Economic Growth: The Case of Kenya, September 2003

1035 A. Lans Bovenberg, Tax Policy and Labor Market Performance, September 2003

1036 Peter Birch Sørensen, Neutral Taxation of Shareholder Income: A Norwegian Tax Reform Proposal, September 2003

1037 Roberta Dessi and Sheilagh Ogilvie, Social Capital and Collusion: The Case of Merchant Guilds, September 2003

1038 Alessandra Casarico and Carlo Devillanova, Capital-skill Complementarity and the Redistributive Effects of Social Security Reform, September 2003

1039 Assaf Razin and Efraim Sadka, Privatizing Social Security Under Balanced-Budget Constraints: A Political-Economy Approach, September 2003

1040 Michele Moretto, Paolo M. Panteghini, and Carlo Scarpa, Investment Size and Firm's Value under Profit Sharing Regulation, September 2003

1041 A. Lans Bovenberg and Peter Birch Sørensen, Improving the Equity-Efficiency Tradeoff: Mandatory Savings Accounts for Social Insurance, September 2003

1042 Bas van Aarle, Harry Garretsen, and Florence Huart, Transatlantic Monetary and Fiscal Policy Interaction, September 2003

1043 Jerome L. Stein, Stochastic Optimal Control Modeling of Debt Crises, September 2003

1044 Thomas Stratmann, Tainted Money? Contribution Limits and the Effectiveness of Campaign Spending, September 2003

1045 Marianna Grimaldi and Paul De Grauwe, Bubbling and Crashing Exchange Rates, September 2003

1046 Assar Lindbeck and Dennis J. Snower, The Firm as a Pool of Factor Complementarities, September 2003

1047 Volker Grossmann, Firm Size and Diversification: Asymmetric Multiproduct Firms under Cournot Competition, September 2003

1048 Dan Anderberg, Insiders, Outsiders, and the Underground Economy, October 2003

1049 Jose Apesteguia, Steffen Huck and Jörg Oechssler, Imitation - Theory and Experimental Evidence, October 2003

1050 G. Abío, G. Mahieu and C. Patxot, On the Optimality of PAYG Pension Systems in an Endogenous Fertility Setting, October 2003 
1051 Carlos Fonseca Marinheiro, Output Smoothing in EMU and OECD: Can We Forego Government Contribution? A Risk Sharing Approach, October 2003

1052 Olivier Bargain and Nicolas Moreau, Is the Collective Model of Labor Supply Useful for Tax Policy Analysis? A Simulation Exercise, October 2003

1053 Michael Artis, Is there a European Business Cycle?, October 2003

1054 Martin R. West and Ludger Wößmann, Which School Systems Sort Weaker Students into Smaller Classes? International Evidence, October 2003

1055 Annette Alstadsaeter, Income Tax, Consumption Value of Education, and the Choice of Educational Type, October 2003

1056 Ansgar Belke and Ralph Setzer, Exchange Rate Volatility and Employment Growth: Empirical Evidence from the CEE Economies, October 2003

1057 Carsten Hefeker, Structural Reforms and the Enlargement of Monetary Union, October 2003

1058 Henning Bohn and Charles Stuart, Voting and Nonlinear Taxes in a Stylized Representative Democracy, October 2003

1059 Philippe Choné, David le Blanc and Isabelle Robert-Bobée, Female Labor Supply and Child Care in France, October 2003

1060 V. Anton Muscatelli, Patrizio Tirelli and Carmine Trecroci, Fiscal and Monetary Policy Interactions: Empirical Evidence and Optimal Policy Using a Structural New Keynesian Model, October 2003

1061 Helmuth Cremer and Pierre Pestieau, Wealth Transfer Taxation: A Survey, October 2003

1062 Henning Bohn, Will Social Security and Medicare Remain Viable as the U.S. Population is Aging? An Update, October 2003

1063 James M. Malcomson, Health Service Gatekeepers, October 2003

1064 Jakob von Weizsäcker, The Hayek Pension: An efficient minimum pension to complement the welfare state, October 2003

1065 Joerg Baten, Creating Firms for a New Century: Determinants of Firm Creation around 1900 , October 2003

1066 Christian Keuschnigg, Public Policy and Venture Capital Backed Innovation, October 2003 